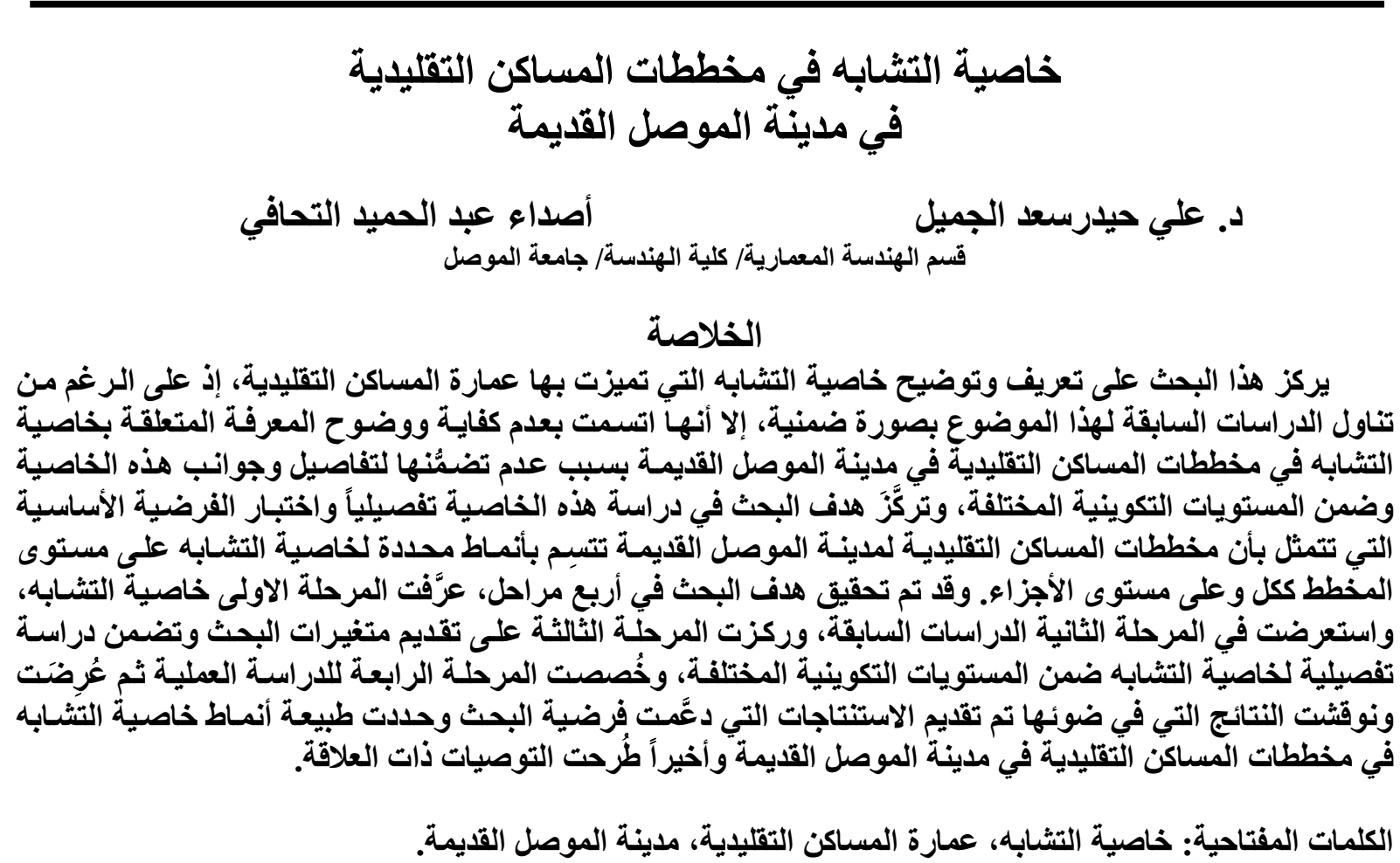

\title{
The Property of Similarity in the Plans of Traditional Houses in Old Mosul City
}

\author{
Dr. Ali H. S. Aljameel \\ Assda A. H. Al-Tuhafi \\ Architecture Dept. / Engineering Col. / University of Mosul
}

\begin{abstract}
This research focuses on defining and clarifying the property of similarity which characterizes the Traditional Houses Architecture, as previous related literature, which has dealt with this issue almost implicitly, is characterized with inadequate and unclear knowledge regarding this property in the plans of traditional houses in old Mosul city. The research aims at studying and elaborating the property of similarity and testing the principle hypothesis that the plans of traditional houses of old Mosul city may be characterized by certain patterns of similarity on both the level of the overall plan composition and the level of plan parts. The research achieved its goal via four stages; the first stage includes the deffinitions of similarity and its related aspects. In the second stage the related previous literature is reviewed in relation with the issue of similarity, while the third stage focuses on introducing elaborated theoretical framework of the research variables within various compositional levels. The fourth stage is dedicated to practical study procedures, presenting and discussing results and finally introducing the conclusions which support the hypothesis of the research and introduce a more detailed definition of the similarity patterns within the plans of traditional houses in old Mosul city in the light of the measured variables and the related recommendations.
\end{abstract}

Key Words: The Property of Similarity, Traditional Houses Architecture, Old Mosul

City.

$$
\text { قبل: } 2013 \text { - } 10 \text { - } 3
$$$$
\text { أستلم: } 2013 \text { - } 6 \text { - } 25
$$ 


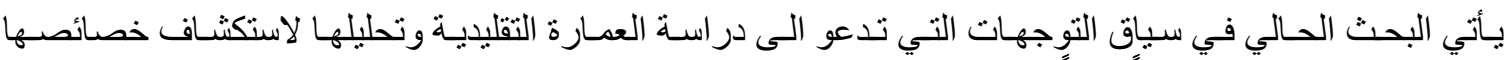

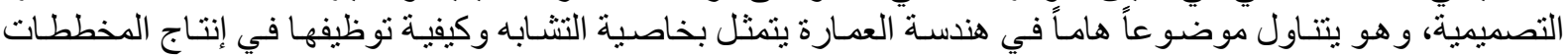

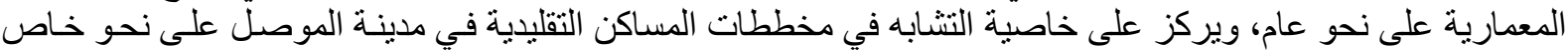
للتوصل الى خصوصيتها من هذه الناحية.

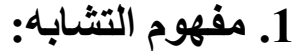

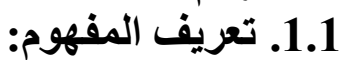

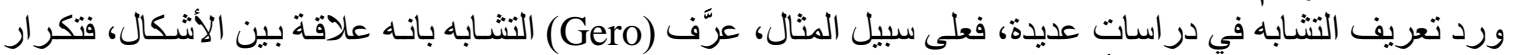

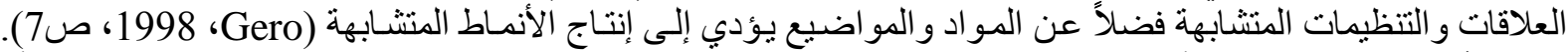

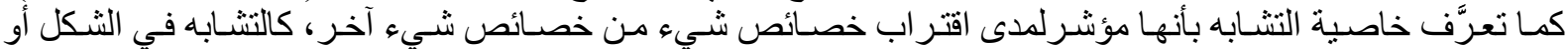

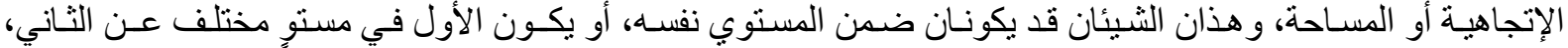
و التثابه من العلاقات المهمة بين الأشكال او الوحدات التهات

\section{1. علاقة خاصية التثابه بتمييز أنماط الثكل:}

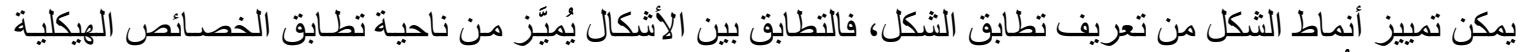

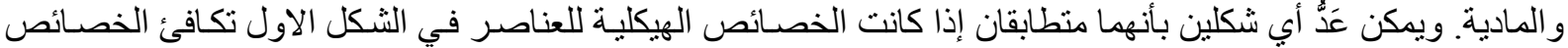

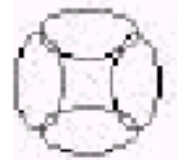

(4)

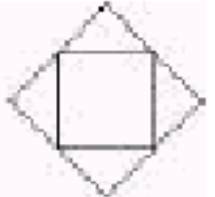

(6)

الثكل (1): الإختلاف في الخصائص في إنصابه

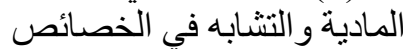

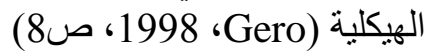

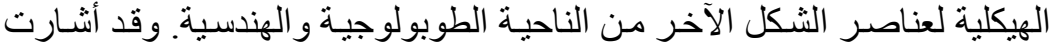

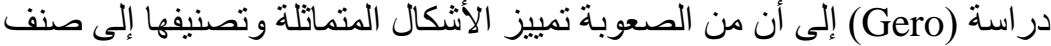

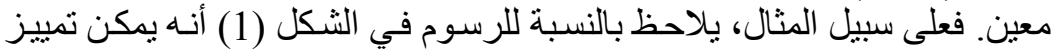

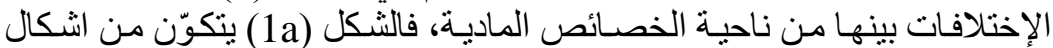

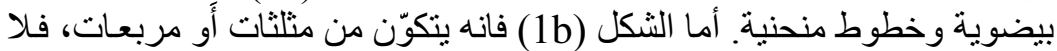

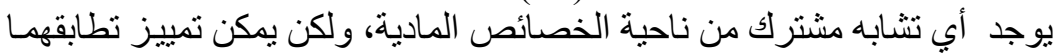

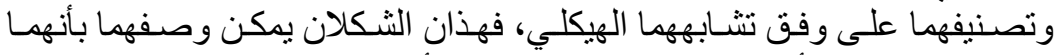

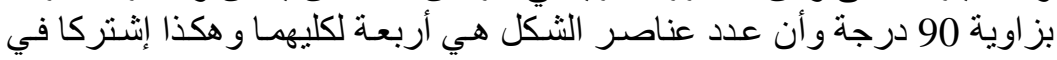

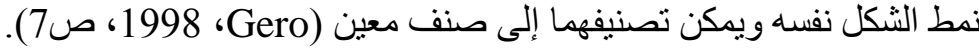

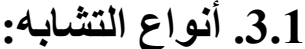

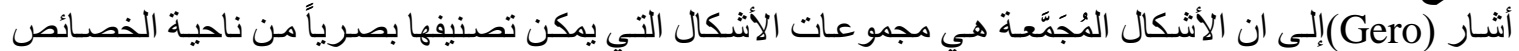

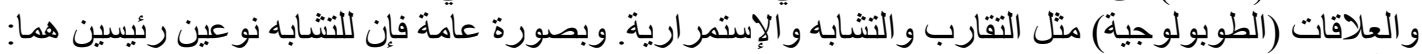

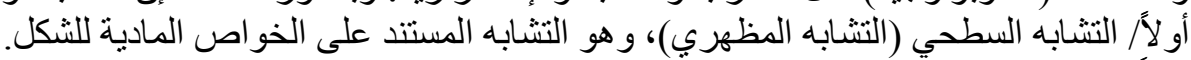

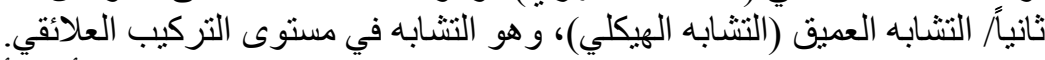

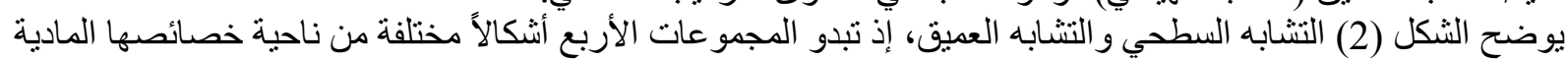

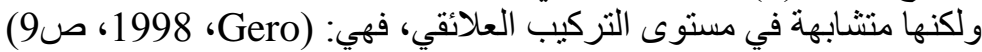
• • متكوّنة من أربعة أشكال منطابقة.

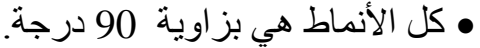

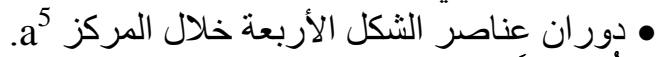

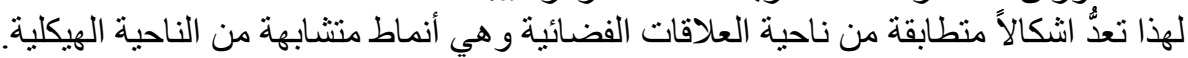

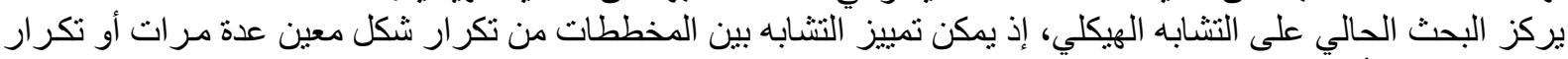

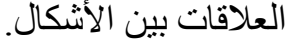

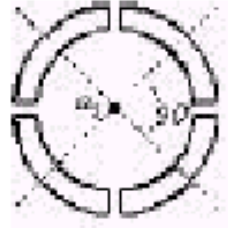

[nil

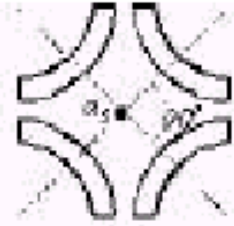

$b$

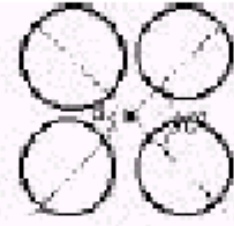

$(2)$

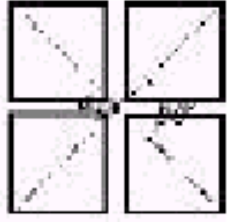

(a)

الثكل (2): التشابه الهيكلي لمجمو عة الأشكال (Gero، 1998، ص9) 


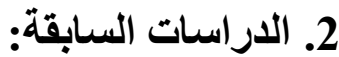

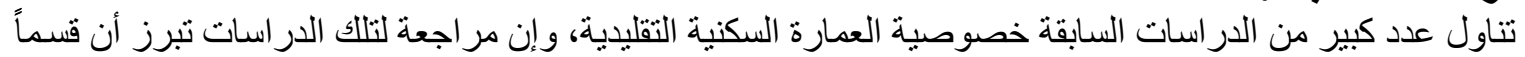

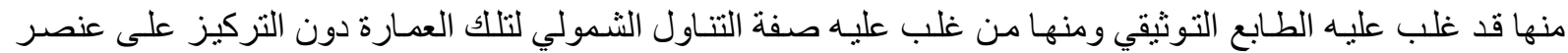

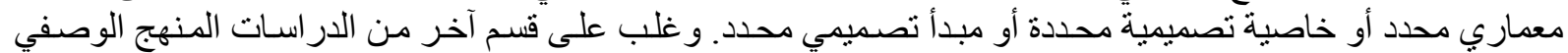

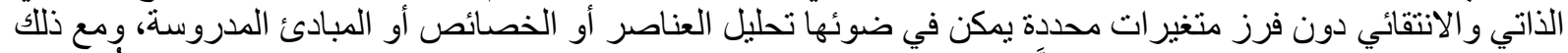

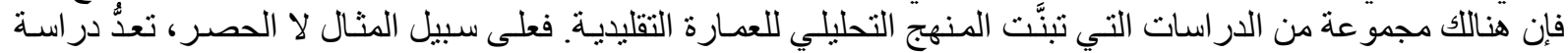

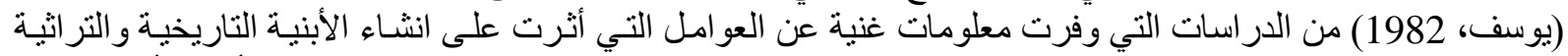

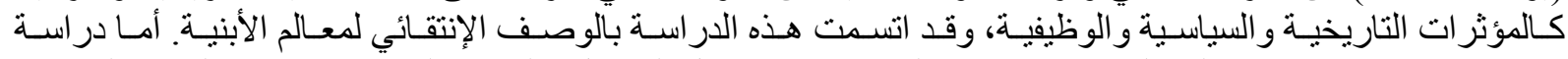
(Herdeg)

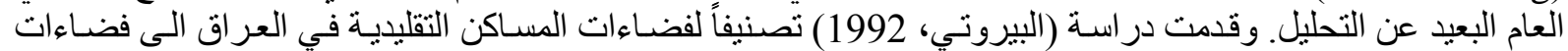

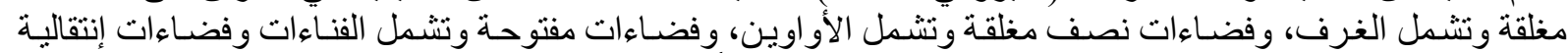

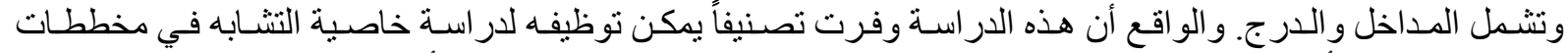

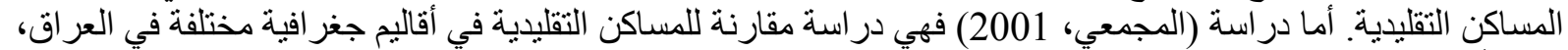

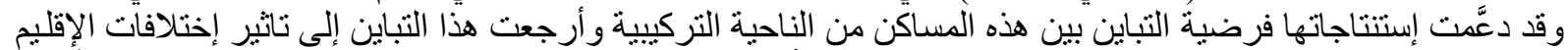

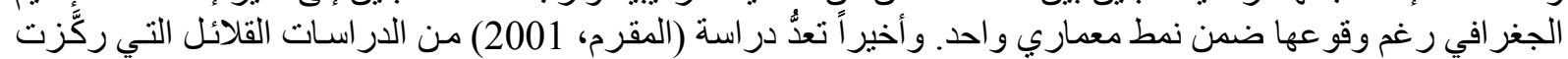

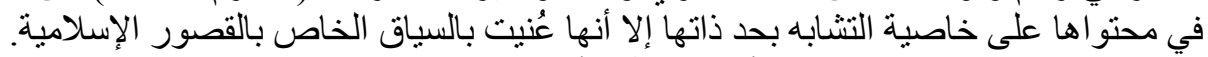

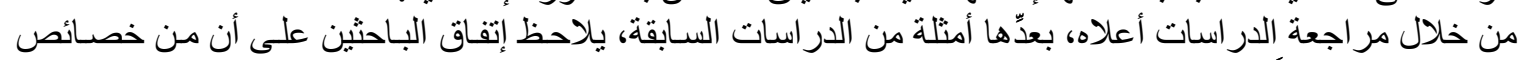

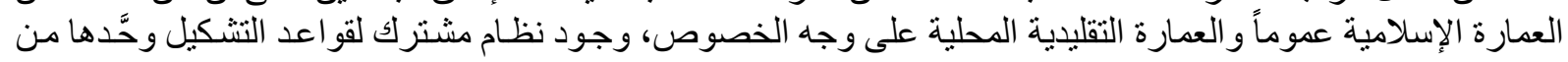

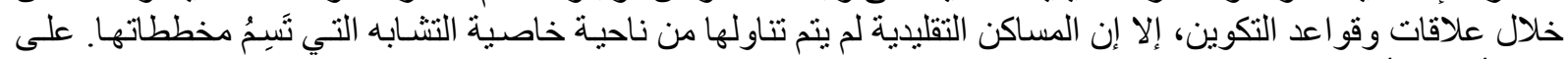

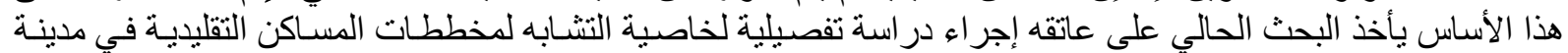
الموصل.

\section{3. مشكلة وهدف وفرضية البحث:}

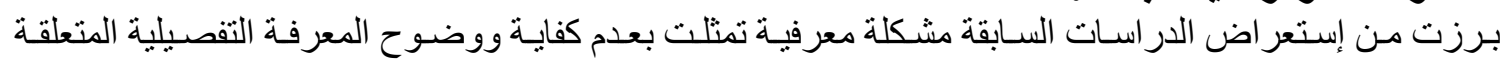

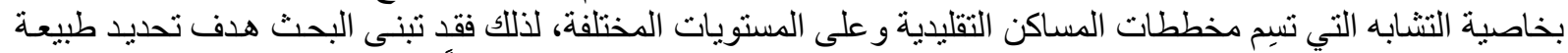

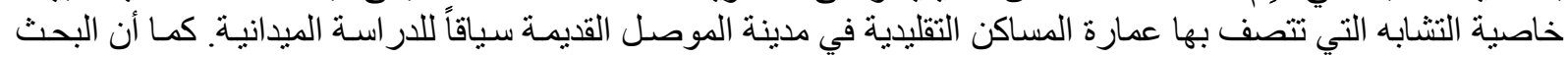

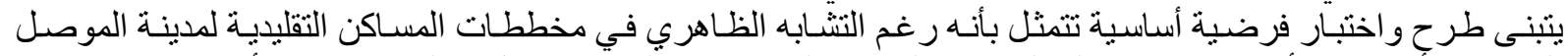

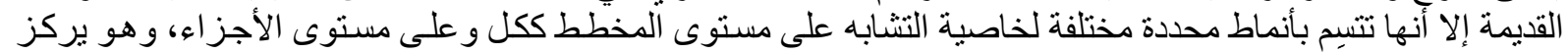

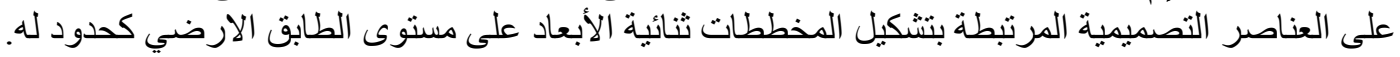

4. مفردات ومتغيرات البحث: مرن:

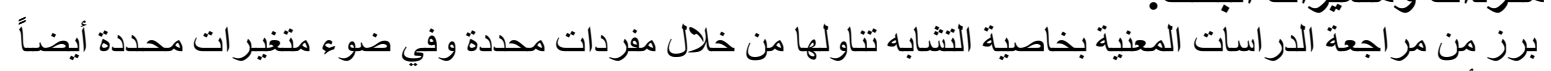
هي كما بأتي:

1.4. التشابه على مستوى أشكال المخططات:

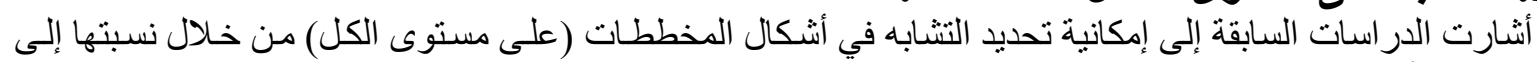

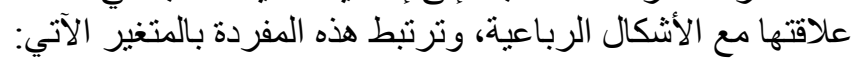

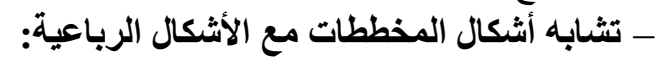

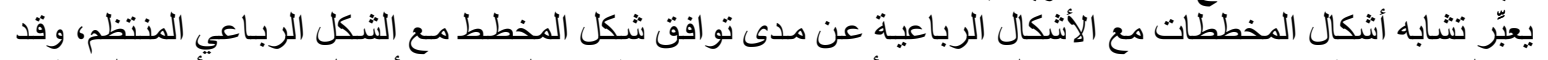

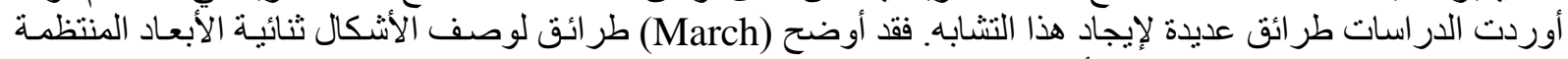

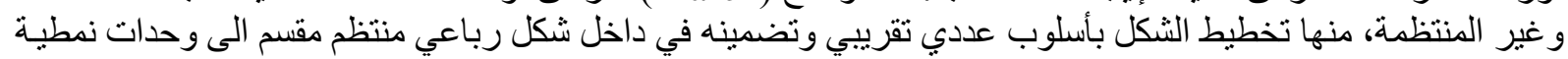

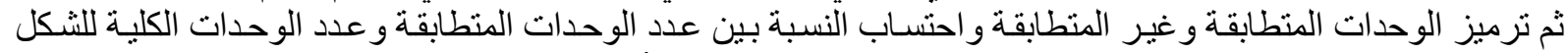

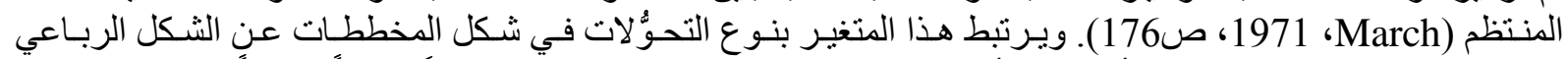

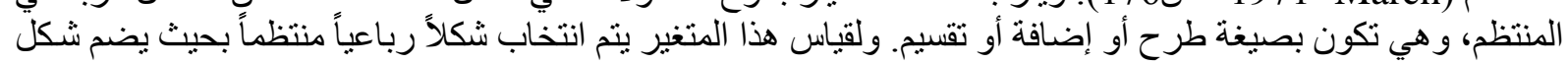

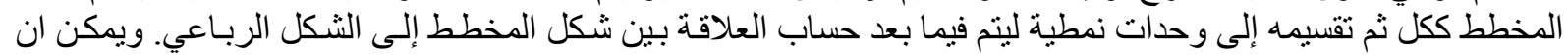

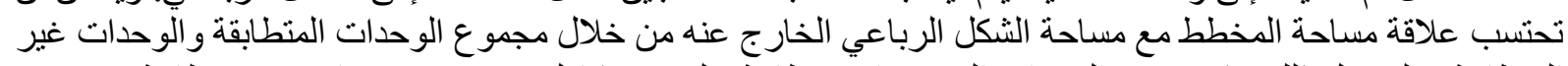

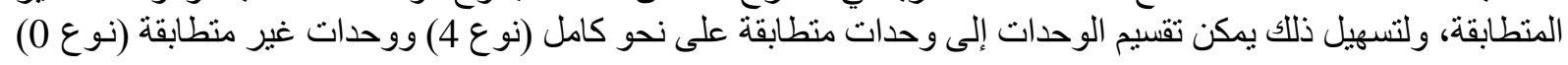




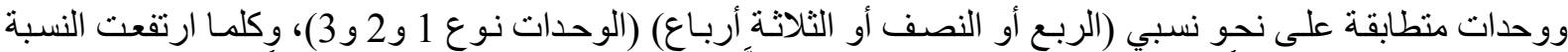

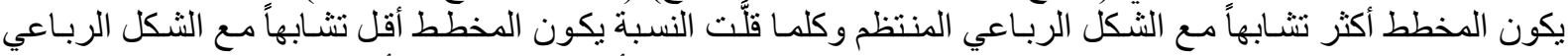

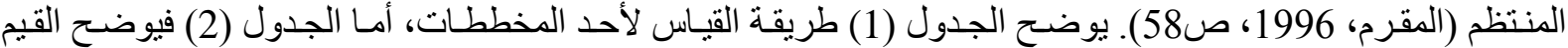
المكنة لمتغير تثنابه شكل المخطط مع الثكل الرباعي.

2 ق المخطط

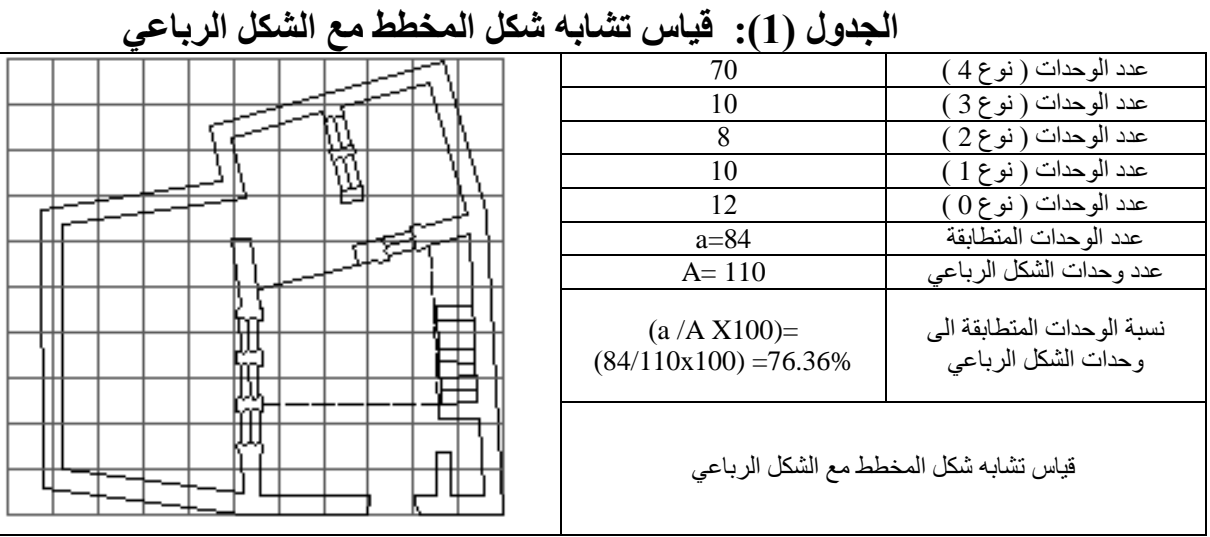

الجدول (2): القيم الممكنة لتشابه شكل المخطط مع الثكل الرباعي

\begin{tabular}{|c|c|c|c|c|c|c|}
\hline القيم الممكنة & رمز القيم & اسم المتغير & رمز المتغير & مجال الخاصبية & مستوى وجود & اسم الخاصية \\
\hline$\% 100$ & $\mathrm{X} 1.1$ & \multirow{7}{*}{ تشابه شكل المخطط مع الرباعي } & \multirow{7}{*}{$\mathrm{X} 1$} & \multirow{7}{*}{ شكل المخطط } & \multirow{7}{*}{ مستوى الكل } & \multirow{7}{*}{ التشابه } \\
\hline بين 90\% و 99\% & $\mathrm{X} 1.2$ & & & & & \\
\hline بين 80\% و 89\% & $\mathrm{X} 1.3$ & & & & & \\
\hline بين 70\% و 79\% & $\mathrm{X} 1.4$ & & & & & \\
\hline بين 60\% و 690\% & $\mathrm{X} 1.5$ & & & & & \\
\hline بين 50\% و 59\% & $\mathrm{X} 1.6$ & & & & & \\
\hline 50\% دون & $\mathrm{X} 1.7$ & & & & & \\
\hline
\end{tabular}

2.4. التشابه على مستوى أشكال الوحدات المكونة للمخططات:

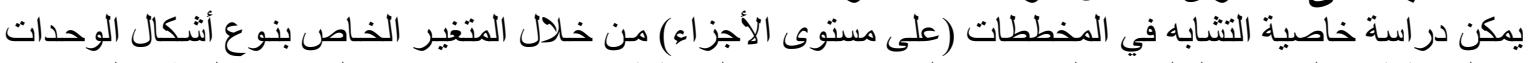

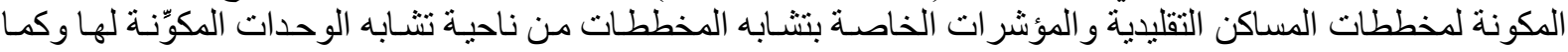

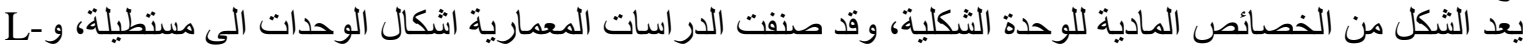
ولك-Shape و Shape

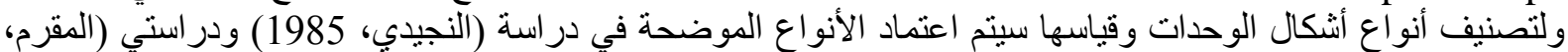

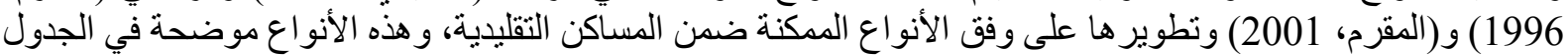

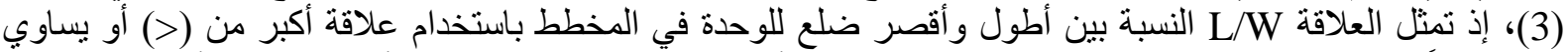

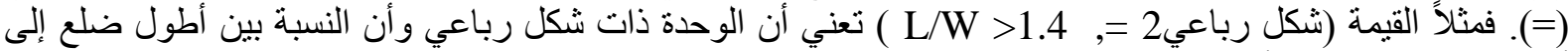

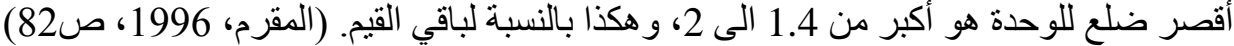

- التثابه في أشكال وحدات المخططات:

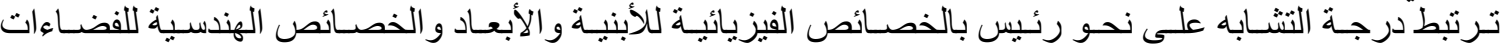

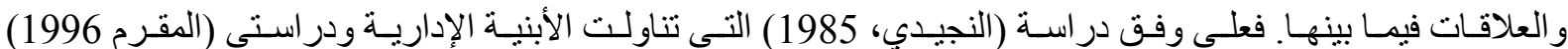

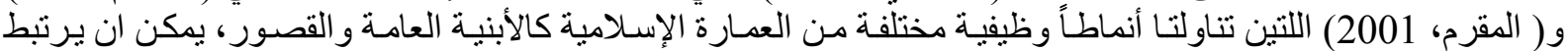

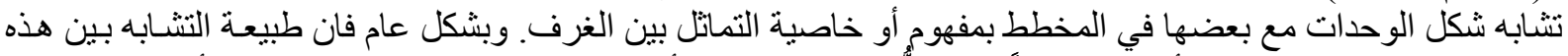

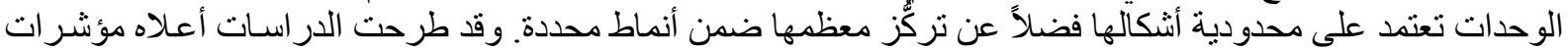

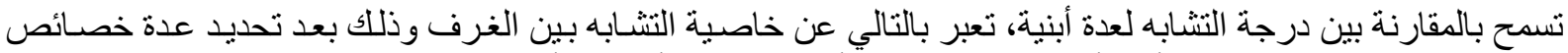

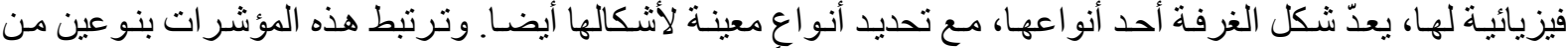

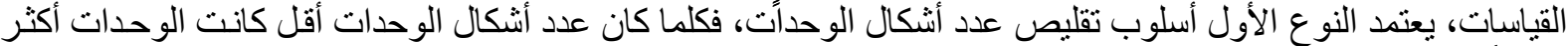
تشابهاً فيما بينها. وباعتماد النسبة بين عدد الوحدات إلى عدد أثكال الوحدات فان درجة التشابه تتر اوح بين قيمة تساوي 
الجميل: خاصية التثابه في مخططات المساكن التقليدية في مدينة الموصل القديمة

الجدول (3): أنواع أشكال الوحدات ضمن المخطط

\begin{tabular}{|c|c|c|c|c|c|c|}
\hline القيم الممكنة & رمز القيم & 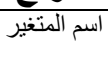 & الرتغير & الخاصبية & مستوى وجود & الخاصية \\
\hline شكل ثلاثي متساوي الاضلاع & $\mathrm{X} 2.1$ & \multirow{19}{*}{ الوح شكل } & \multirow[t]{19}{*}{$\mathrm{X} 2$} & \multirow{19}{*}{ المخكات المخطنة } & \multirow{19}{*}{ الأجزاء } & \multirow[t]{19}{*}{ التثابه } \\
\hline شكل ثلاثي متساوي الساقين & $\mathrm{X} 2.2$ & & & & & \\
\hline شكل ثلاثي مختلف الاضلاع & $\mathrm{X} 2.3$ & & & & & \\
\hline شكل رباعي 1:1 = ش & $\mathrm{X} 2.4$ & & & & & \\
\hline شكل رباعي 1.4 = , L/W >1 & $\mathrm{X} 2.5$ & & & & & \\
\hline شكل رباعي 2=, L/W > 1.4 & $\mathrm{X} 2.6$ & & & & & \\
\hline شكل رباعي $4=$ = , L/W & $\mathrm{X} 2.7$ & & & & & \\
\hline شكل رباعي 4 اع & $\mathrm{X} 2.8$ & & & & & \\
\hline 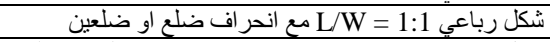 & $\mathrm{X} 2.9$ & & & & & \\
\hline شكل رباعي $1.4=1$, L/W > مع انحر اف ضلع او ضلعين & $\mathrm{X} 2.10$ & & & & & \\
\hline شكل رباعي $2=1.4$, L/W >1.4 مع انحر اف ضلع او ضلعين & $\mathrm{X} 2.11$ & & & & & \\
\hline شكل رباعي $4=$ =, L/W > مع انحر اف ضلع او ضلعين & $\mathrm{X} 2.12$ & & & & & \\
\hline شكل رباعي L/W > مع انحر اف ضلع او ضلعين & $\mathrm{X} 2.13$ & & & & & \\
\hline شكل L منتظم & $\mathrm{X} 2.14$ & & & & & \\
\hline شكل U منتظم & $\mathrm{X} 2.15$ & & & & & \\
\hline شكل L مع انحر اف ضلع او ضلعين & $\mathrm{X} 2.16$ & & & & & \\
\hline شكل U مع انحر اف ضلع او ضلعين & $\mathrm{X} 2.17$ & & & & & \\
\hline شكل غير منتظم منحرف الاضلاع & $\mathrm{X} 2.18$ & & & & & \\
\hline شكل غير منتظم متعامد الاضلاع & $\mathrm{X} 2.19$ & & & & & \\
\hline
\end{tabular}

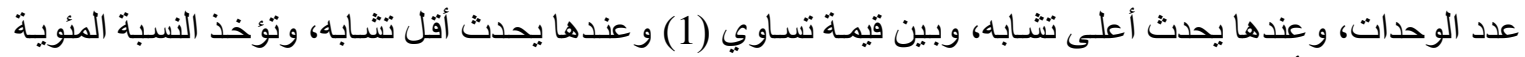
لغرض المقارنة بين الأبنية المختلفة، وهذا موضح في المعادلاتهات (1) و(2). 100 x درجة التشابه= (عدد الوحدات ضمن المخطط/ عدد أشنكال الوحدات)

وبفرض أن: Y= عدد اثـكال الوحدات، X= عدد الوحدات ضـمن المخطط، فيمكن صبياغة المعادلـة السـابقة بالثـكل الرياضي الآتي:

$$
100 \text { x (Y /X)=درجة التشابه }
$$

ونظراً لاختلاف كل من أشكال الوحدات وأعداد الوحدات ضمن الأبنية المختلفة، فإنه يمكن اللجوء الى المعادلة (3): المؤشر الاول=[(عدد الوحدات ضمن المخطط ـ عدد أنشكال الوحدات)/ \}(عدد الوحدات ضمن المخطط xدد أنشكال

وبفرض أن: Y= عدد اشكال الوحدات، X X = عدد الوحدات ضـمن المخطط، فيمكن صياغة المعادلـة السـابقة بالشكل

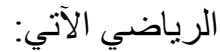

$$
100 \text { x[(Y - X Y)/( Y - X)]= المؤشر الأول }
$$

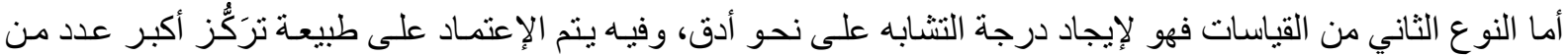

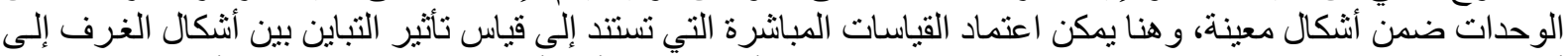

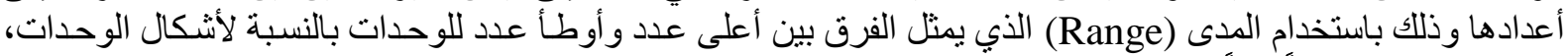
ويمكن اعتبار هؤشر أشاً نانياً.

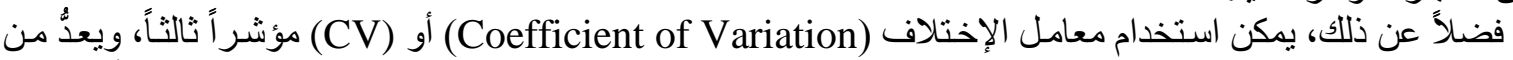

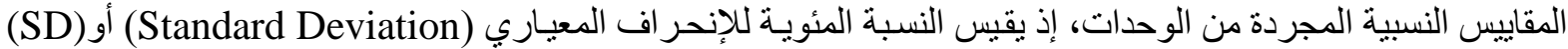

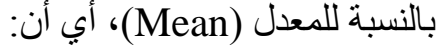

$\mathrm{CV}=\mathrm{SD} / \mathrm{Mean} \times 100 \%$

$$
\text { ولما كان المعدل (Mean) يساوي (X/Y) في هذه الحالة، لذا يكون القانون الاخير بالثكل الاتي: }
$$


$\mathrm{CV}=\mathrm{SD} /(\mathrm{X} / \mathrm{Y}) \times 100 \%$

ويصلح المؤشران الأخير ان للمقارنة بين الأبنية التي لا تختلف على نحو كبير في أشكال الوحدات.

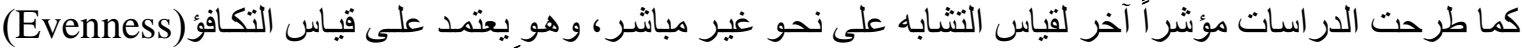

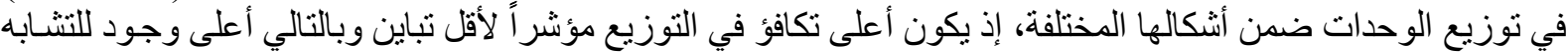
بين الأبنية الخاضعة للمقارنة، ويعتمد على المعادلة الآتية:

$\mathrm{E}=(\mathrm{Y} / \mathrm{E}) \times 100 \%=\mathrm{Y} \times \mathrm{Y} /[\mathrm{X}(\operatorname{Sum}(1 / \mathrm{xy}))] \times 100 \%$

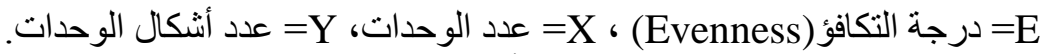

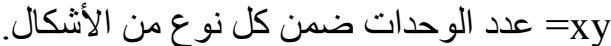

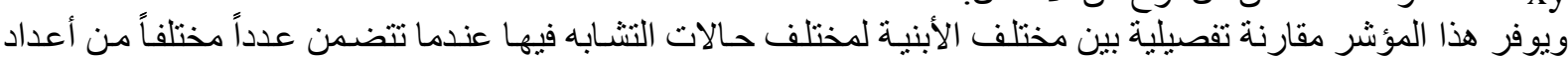

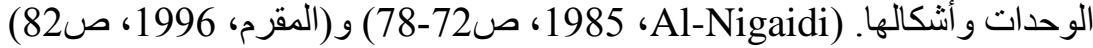

5. إجراءات الار اسة العملية:

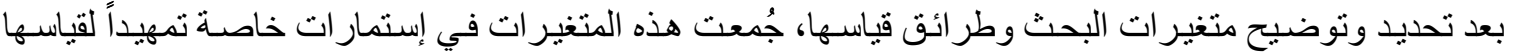

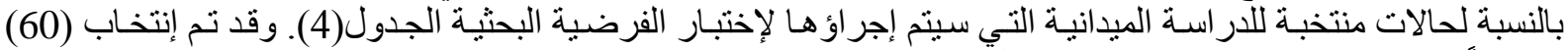

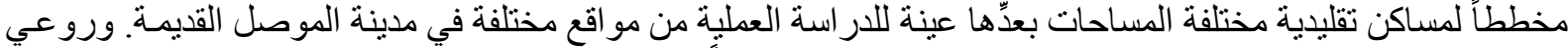

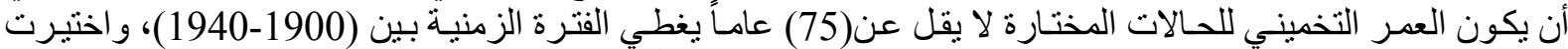

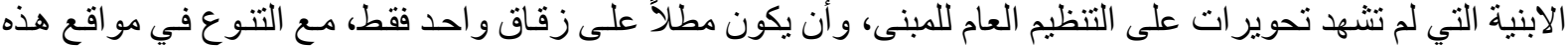
الابنية ومساحتها و عدد وحداتها (فضاء التهاتها).

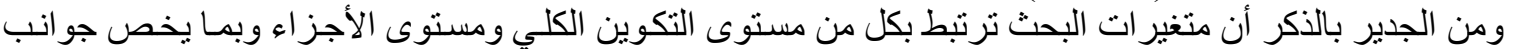

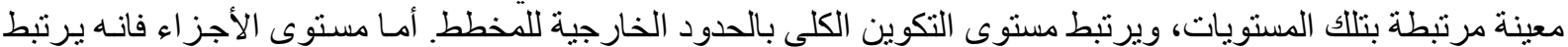

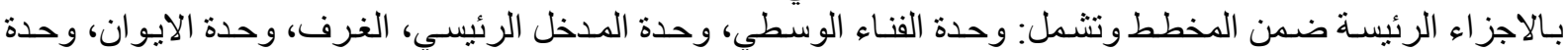

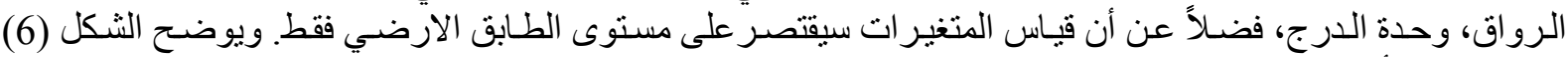

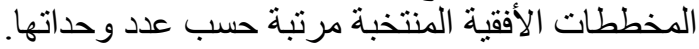
الجدول (4): إستمارة قياس المتغيرات

\begin{tabular}{|c|c|c|c|c|c|c|}
\hline \multirow{3}{*}{ الحالات } & \multirow[b]{3}{*}{ القيم الممكنة } & \multirow[b]{3}{*}{ 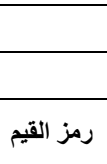 } & \multicolumn{2}{|c|}{ مساحة العقار } & \multicolumn{2}{|c|}{ رقم المخطط } \\
\hline & & & \multicolumn{2}{|c|}{ عدد الوحدات ضمن المخطط } & \multicolumn{2}{|c|}{ اسم المحلة و رقم العقار } \\
\hline & & & 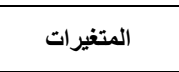 & رمز المتغير & مستوى وجود & الخاصية \\
\hline & $\% 100$ & $\mathrm{X} 1.1$ & \multirow{7}{*}{ المخطظ مع الثكل } & \multirow{7}{*}{$\mathrm{X} 1$} & \multirow{7}{*}{ مستوى الكل } & \multirow{7}{*}{ التشابه } \\
\hline & 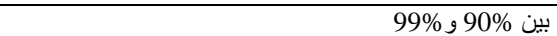 & $\mathrm{X} 1.2$ & & & & \\
\hline & 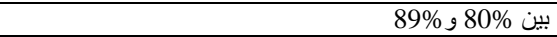 & $\mathrm{X} 1.3$ & & & & \\
\hline & 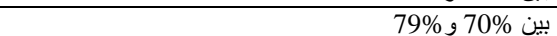 & $\mathrm{X} 1.4$ & & & & \\
\hline & 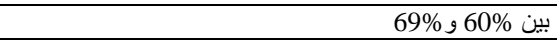 & $\mathrm{X} 1.5$ & & & & \\
\hline & 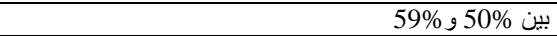 & $\mathrm{X} 1.6$ & & & & \\
\hline & 5ون 50\% & $\mathrm{X} 1.7$ & & & & \\
\hline & شكل ثلاثى منساوي الاضلاع & $\mathrm{X} 2.1$ & \multirow{19}{*}{ 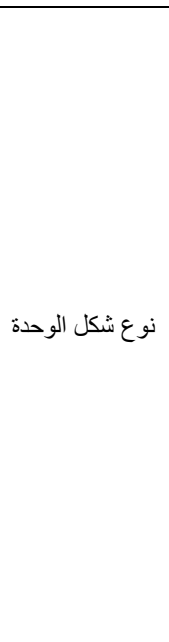 } & \multirow{19}{*}{$\mathrm{X} 2$} & \multirow{19}{*}{ الاجزتوى } & \multirow{19}{*}{ التشابه } \\
\hline & شكل ثلاثي متساوي الساقين & $\mathrm{X} 2.2$ & & & & \\
\hline & شكل ثلاثي مختلف الاضلاع & $\mathrm{X} 2.3$ & & & & \\
\hline & شكل رباعي 1:1 = ش & $\mathrm{X} 2.4$ & & & & \\
\hline & شكل رباعي 1.4 = , L1W >1 & $\mathrm{X} 2.5$ & & & & \\
\hline & شكل رباعي 2=, L/W >1.4 & $\mathrm{X} 2.6$ & & & & \\
\hline & شكل رباعي $4=$ = , L/W > & $\mathrm{X} 2.7$ & & & & \\
\hline & شكل رباعى 4 اع & $\mathrm{X} 2.8$ & & & & \\
\hline & شكل رباعي L/W = 1:1 مع انحر اف ضلع او ضلعين & $\mathrm{X} 2.9$ & & & & \\
\hline & شكل رباعي 1.4 = , L/W > مع انحر اف ضلع او ضلعين & $\mathrm{X} 2.10$ & & & & \\
\hline & شكل رباعي $2=1.4$, L/W >1 مع انحر اف ضلع او ضلعين & $\mathrm{X} 2.11$ & & & & \\
\hline & شكل رباعي 4 =, , L/W > مع انحر اف ضلع او ضلعين & $\mathrm{X} 2.12$ & & & & \\
\hline & شكل رباعي L/W > مع انحر اف ضلع او ضلعين & $\mathrm{X} 2.13$ & & & & \\
\hline & شكل L منتظم & $\mathrm{X} 2.14$ & & & & \\
\hline & شكل U منظظم & $\mathrm{X} 2.15$ & & & & \\
\hline & شكل L مع انحر اف ضلع او ضلعين & $\mathrm{X} 2.16$ & & & & \\
\hline & شكل U مع انحر اف ضلع او ضلعين & $\mathrm{X} 2.17$ & & & & \\
\hline & شكل غير منتظم منحرف الاضلاع & $\mathrm{X} 2.18$ & & & & \\
\hline & شكل غير منتظم متعامد الاضلاع & $\mathrm{X} 2.19$ & & & & \\
\hline
\end{tabular}




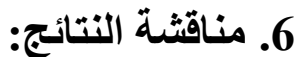

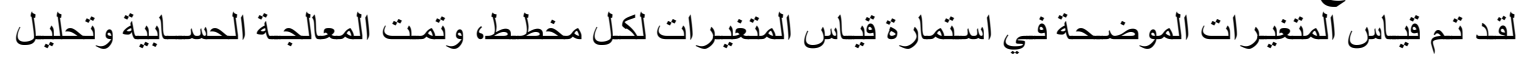

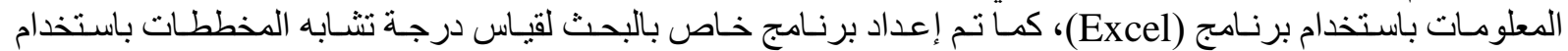

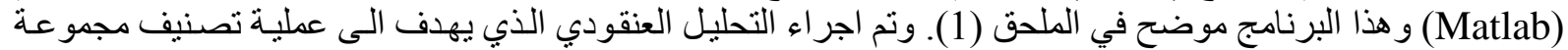

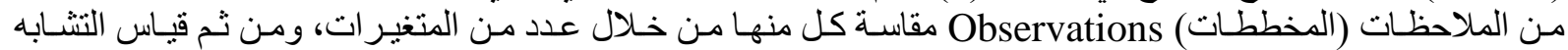

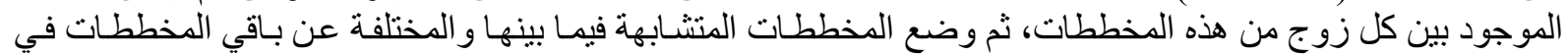

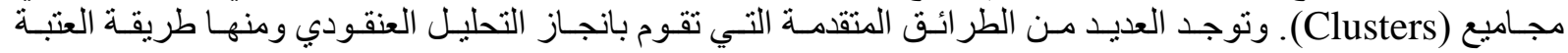

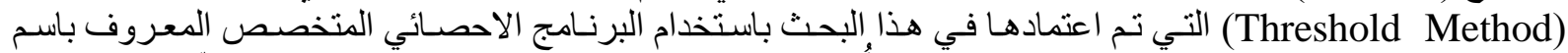

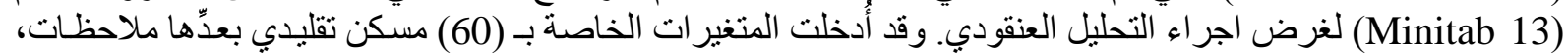

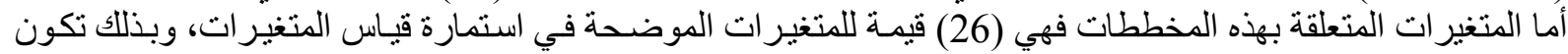

البيانات المدخلة للبرنامج هي 1560 x60

\section{أولاً: النتائج الخاصة بتشابه أثكال المخططات مع الأثكال الرباعية}

يوضح الجدول (5) و الثكل (4) النتائج الخاصة بتشابه أثكال المخططات مع الأشكال الرباعية:

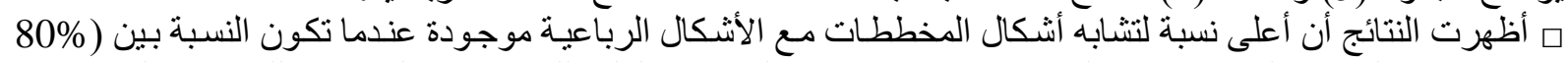

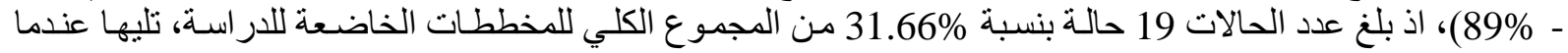

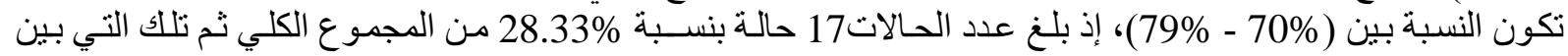

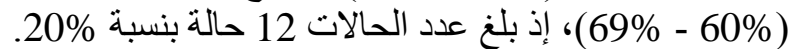

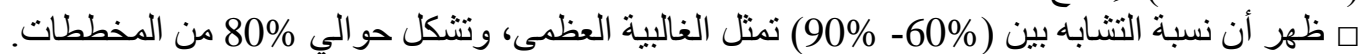
ه ظهر أن النسبة بين (90\% - 99\%) بلغت 7 حالات وشكلت نسبة 11.66\%، وان النسبة بين (50\%- 59\%) بلغت 5

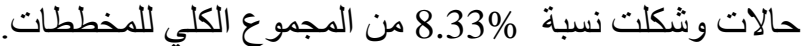
口 أوضحت النتائج انه لم تسجل أية حالة لنسبة التشابه 100\% وكذلك دون 50\%.

\begin{tabular}{|c|c|c|c|}
\hline النسب المئوية من المجموع الكلي & عدد الحالات الملاحظة من المجموع المخطات & نسب تثابه الثكال المخططات مع الاشكال & 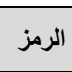 \\
\hline $0 \%$ & 0 & $\% 100$ & $\mathrm{X} 1.1$ \\
\hline $11.66 \%$ & 7 & بين 90\% و 990\% & $\mathrm{X} 1.2$ \\
\hline $31.66 \%$ & 19 & بين 80\% و 89\% & $\mathrm{X} 1.3$ \\
\hline $28.33 \%$ & 17 & 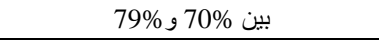 & $\mathrm{X} 1.4$ \\
\hline $20 \%$ & 12 & بين 60\% و 69\% & $\mathrm{X} 1.5$ \\
\hline $8.33 \%$ & 5 & بين 50\% و 59\% & $\mathrm{X} 1.6$ \\
\hline $0 \%$ & 0 & دون 50\% & X1.7 \\
\hline
\end{tabular}

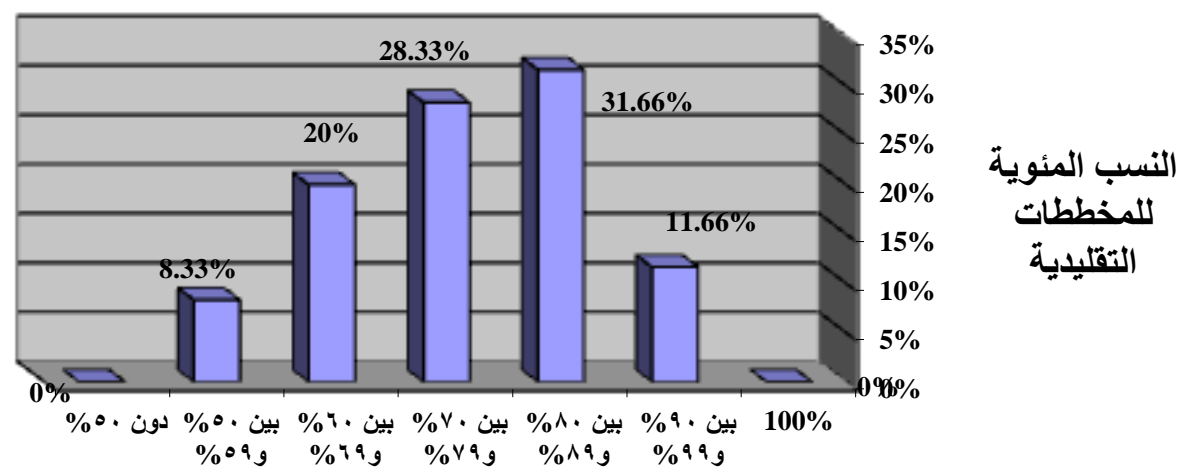

الثكل (3): النتائج الخاصة بنسب تشابه أشكال مخططات المساكن التقليدية مع الأشكال الرباعية 


\section{يوضح الجدول (6) و الثكل (4) النتائج الخاصة بأنو اع أنثال الوحدات وكما يأتي:}

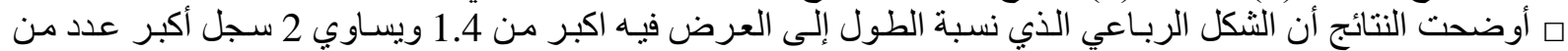

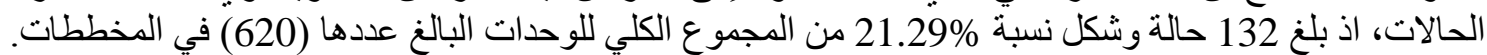

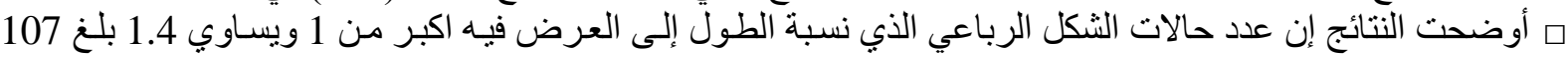

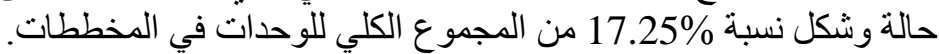

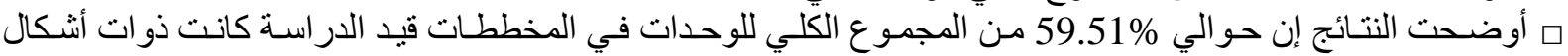

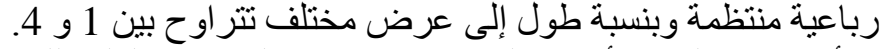

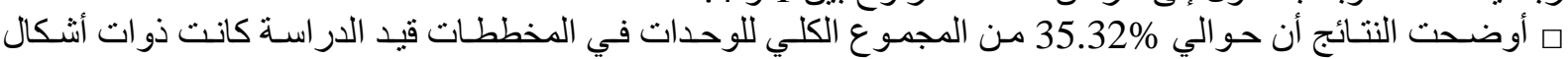

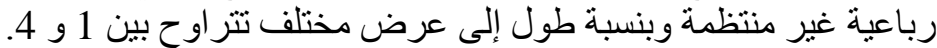
ه أوضحت النتائج أن نسبة بقية الأشكال لاتجاوز 5.16\% من المجموع الكلي للوحدات في المخططات.

الجدول (6): النتائج الخاصة بأنواع أشكال الوحدات

\begin{tabular}{|c|c|c|c|}
\hline النسب المئوية من المجموع الكلي & المجموع الكلي للمخططات الماتلة من & أثكال الوحدات & 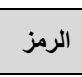 \\
\hline $0 \%$ & 0 & شكل ثلاثي متساوي الاضضلاع & $\mathrm{X} 2.1$ \\
\hline $0.64 \%$ & 4 & شكل ثلاثي متساو & $\mathrm{X} 2.2$ \\
\hline $0.32 \%$ & 2 & شكل ثلاثي مختلف الأضلاع & $\mathrm{X} 2.3$ \\
\hline $3.22 \%$ & 20 & L/W = شكل رباعي 1:1 & $\mathrm{X} 2.4$ \\
\hline $17.25 \%$ & 107 & 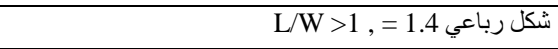 & $\mathrm{X} 2.5$ \\
\hline $21.29 \%$ & 132 & شكل رباعي $2=1.4$ = 1.4 & $\mathrm{X} 2.6$ \\
\hline $12.90 \%$ & 80 & L/W > شكل رباعي $4=$ & $\mathrm{X} 2.7$ \\
\hline $4.83 \%$ & 30 & شكل رباعي 4 ا & $\mathrm{X} 2.8$ \\
\hline $1.12 \%$ & 7 & شكل رباعي L/W = 1:1 مع انحر اف ضلع أو ضلعين & $\mathrm{X} 2.9$ \\
\hline $14.19 \%$ & 88 & شكل رباعي 1.4 = , L/W > مع انحر اف ضلع أو ضلعين & $\mathrm{X} 2.10$ \\
\hline $15 \%$ & 93 & شكل رباعي $2=$ = , L/W >1.4 مع انحر اف ضلع أو ضلعين & $\mathrm{X} 2.11$ \\
\hline $4.19 \%$ & 26 & شكل رباعي 4 =, , L/W > مع انحر اف ضلع أو ضلعين & $\mathrm{X} 2.12$ \\
\hline $0.80 \%$ & 5 & شكل رباعي 4 > مع انحر اف ضلع أو ضلعين & $\mathrm{X} 2.13$ \\
\hline $1.12 \%$ & 7 & شكل L منتظم & $\mathrm{X} 2.14$ \\
\hline $0 \%$ & 0 & شكل U منتظم & $\mathrm{X} 2.15$ \\
\hline $1.29 \%$ & 8 & شكل L مع انحر اف ضلع أو ضلعين & $\mathrm{X} 2.16$ \\
\hline $0 \%$ & 0 & شكل U مع انحر اف ضلع أو ضلعين & $\mathrm{X} 2.17$ \\
\hline $1.29 \%$ & 8 & شكل غير منتظم منحرف الأضلاع & $\mathrm{X} 2.18$ \\
\hline $0.48 \%$ & 3 & شكل غير منتظم متعامد الأضلاع & $\mathrm{X} 2.19$ \\
\hline
\end{tabular}

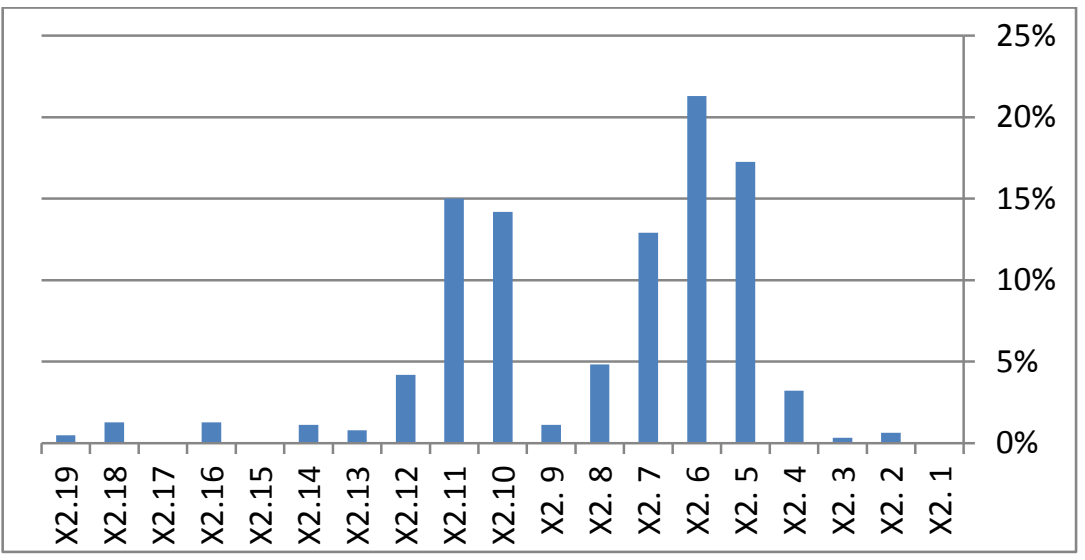

$$
\text { الثكل (4): النتائج الخاصة بنوع أثنكال الوحدات }
$$




\section{ثالثاً: النتائج الخاصة بتثابه المخططات من ناحية أنواع أشكال الوحدات المكونة لها}

يوضح الجدول (7) النتائج الخاصة بتثابه المخططات من ناحية أشكال الوحدات المكونة لها وكما يأتي:

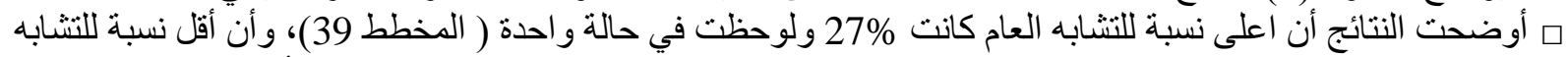

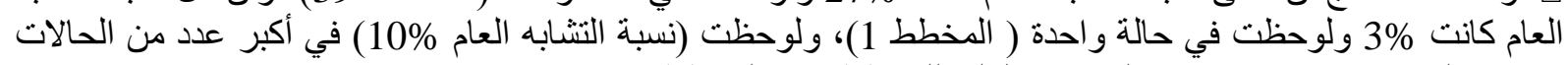

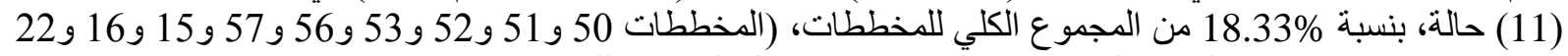
و23 و 25)، وترتبط نسب التشابه العام بمدى تقلليص انو الماع الشكال الوحدات للمخطط.

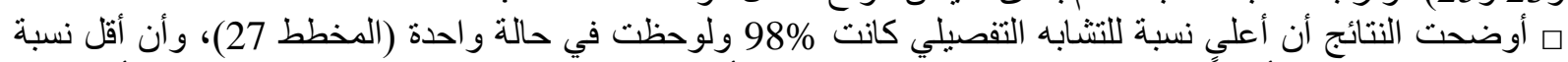

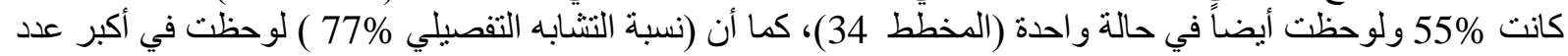

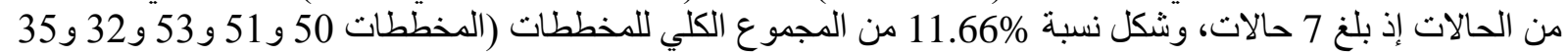

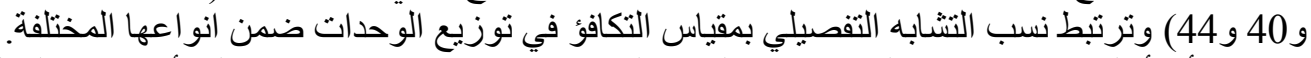

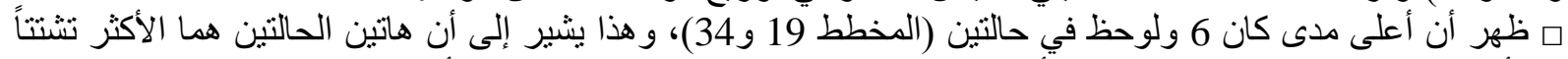

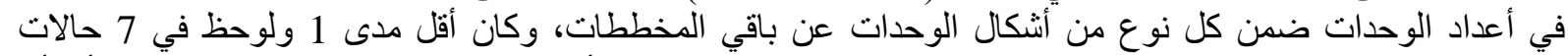

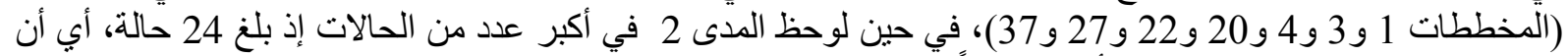

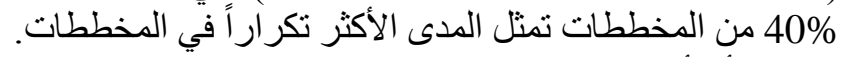

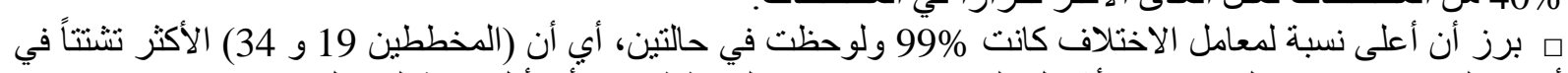

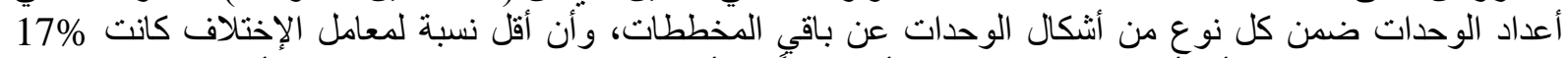

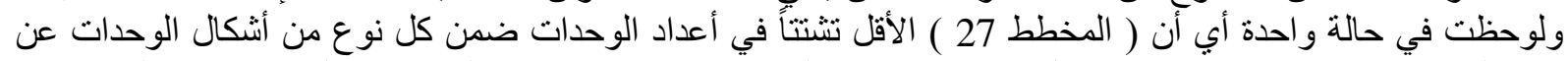

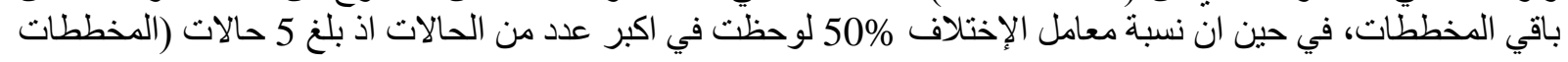

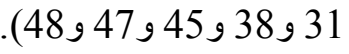

الجدول (7): النتائج الخاصة بدرجة تثابه المخطظات بالنسبة لأشكال الوحدات

\begin{tabular}{|c|c|c|c|c|c|c|c|c|c|c|c|c|c|c|c|c|}
\hline \multicolumn{15}{|c|}{ ارقام المخططات الخاضعة للار اسة العملية } & \multirow{2}{*}{ 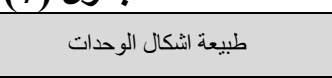 } & \multirow{2}{*}{ الرمز } \\
\hline 15 & 14 & 13 & 12 & 11 & 10 & 9 & 8 & 7 & 6 & 5 & 4 & 3 & 2 & 1 & & \\
\hline & & & & & & & & & & & & & & & شكل ثلاثي متساوي الاضلاع & $\mathrm{X} 2.1$ \\
\hline & & & & & & & & & & & & & & & شكل ثلاثي متساوي الساقين & $\mathrm{X} 2.2$ \\
\hline & & & & & & & & & & & & & & & شكل ثلاثي مختلف الاضلاع & $\mathrm{X} 2.3$ \\
\hline & & & 1 & 1 & 1 & & & & & & 1 & & & 1 & شكل رباعي 1:1 = ش ش & $\mathrm{X} 2.4$ \\
\hline 1 & 1 & 3 & 1 & & 2 & & & 2 & 2 & 1 & 2 & 2 & & 1 & شكل رباعي 1.4 = , L1/W & $\mathrm{X} 2.5$ \\
\hline 4 & 1 & & 4 & & 3 & & & 4 & & & 1 & 1 & 4 & & شكل رباعي $2=, 1.4$ ا & $\mathrm{X} 2.6$ \\
\hline \multirow[t]{2}{*}{1} & 4 & & 1 & 1 & 2 & 1 & 1 & 2 & 1 & 1 & 1 & 1 & & 2 & شكل رباعي $4=2,2 / W>2$ & $\mathrm{X} 2.7$ \\
\hline & & & & & & & & & & 1 & & 1 & & & شكل رباعي 4 L/W & $\mathrm{X} 2.8$ \\
\hline \multirow[t]{2}{*}{1} & & & & & & & & & & & & & & & 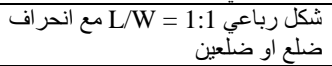 & $\mathrm{X} 2.9$ \\
\hline & 1 & 2 & 1 & 4 & & 2 & 3 & & 3 & 1 & & & 1 & 1 & 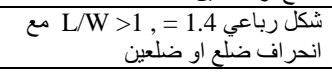 & $\mathrm{X} 2.10$ \\
\hline \multirow[t]{9}{*}{2} & & 1 & & 1 & & 3 & 3 & & & 3 & 2 & 2 & 1 & 1 & 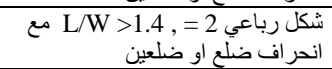 & $\mathrm{X} 2.11$ \\
\hline & 1 & 1 & & 1 & & 2 & 1 & & 1 & & & & 1 & 1 & 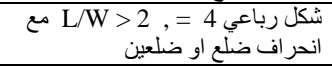 & $\mathrm{X} 2.12$ \\
\hline & & & & & & & & & & & & & & & ضلع او ضلعين > L/W مع انحر اف & $\mathrm{X} 2.13$ \\
\hline & & & & & & & & & & & & & & & شكل L منتظم & $\mathrm{X} 2.14$ \\
\hline & & & & & & & & & & & & & & & شكل U منتظم & $\mathrm{X} 2.15$ \\
\hline & & & & & & & & & & & & & & & شكل L مع انحر اف ضلع او ضلعين & $\mathrm{X} 2.16$ \\
\hline & & & & & & & & & & & & & & & شكل U مع انحر اف ضلّع او ضلعبين & $\mathrm{X} 2.17$ \\
\hline & & 1 & & & & & & & & & & & & & شكل غير منتظم منحرف الاضلاع & $\mathrm{X} 2.18$ \\
\hline & & & & & & & & & & & & & & & شكل غير منتظم متعامد الاضلاع & $\mathrm{X} 2.19$ \\
\hline 5 & 5 & 5 & 5 & 5 & 4 & 4 & 4 & 3 & 4 & 5 & 5 & 5 & 4 & 6 & \multicolumn{2}{|l|}{ عداد اشكال الوحدات Y ع ب } \\
\hline 9 & 8 & 8 & 8 & 8 & 8 & 8 & 8 & 8 & 7 & 7 & 7 & 7 & 7 & 7 & \multicolumn{2}{|l|}{ X عدد الوحدات X } \\
\hline 10 & 9 & 9 & 9 & 9 & 14 & 14 & 14 & 24 & 13 & 7 & 7 & 7 & 13 & 3 & $\mathrm{X}-\mathrm{Y}$ & \multirow{2}{*}{ 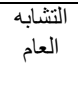 } \\
\hline$\%$ & $\%$ & $\%$ & $\%$ & $\%$ & $\%$ & $\%$ & $\%$ & $\%$ & $\%$ & $\%$ & $\%$ & $\%$ & $\%$ & $\%$ & $\overline{\mathrm{XY}} \%$ & \\
\hline 3 & 3 & 2 & 3 & 3 & 2 & 2 & 2 & 2 & 2 & 2 & 1 & 1 & 3 & 1 & Range المدى & \\
\hline 72 & 84 & 56 & 84 & 84 & 41 & 41 & 58 & 43 & 55 & 64 & 39 & 39 & 86 & 35 & Cofficient of معامل الثباين & \\
\hline$\%$ & $\%$ & $\%$ & $\%$ & $\%$ & $\%$ & $\%$ & $\%$ & $\%$ & $\%$ & $\%$ & $\%$ & $\%$ & $\%$ & $\%$ & Variation & \\
\hline 74 & 74 & 82 & 74 & 74 & 86 & 86 & 75 & 90 & 81 & 82 & 89 & 89 & 70 & 94 & درجة التكافؤ Evenness & التفيلي \\
\hline$\%$ & $\%$ & $\%$ & $\%$ & $\%$ & $\%$ & $\%$ & $\%$ & $\%$ & $\%$ & $\%$ & $\%$ & $\%$ & $\%$ & $\%$ & & \\
\hline
\end{tabular}




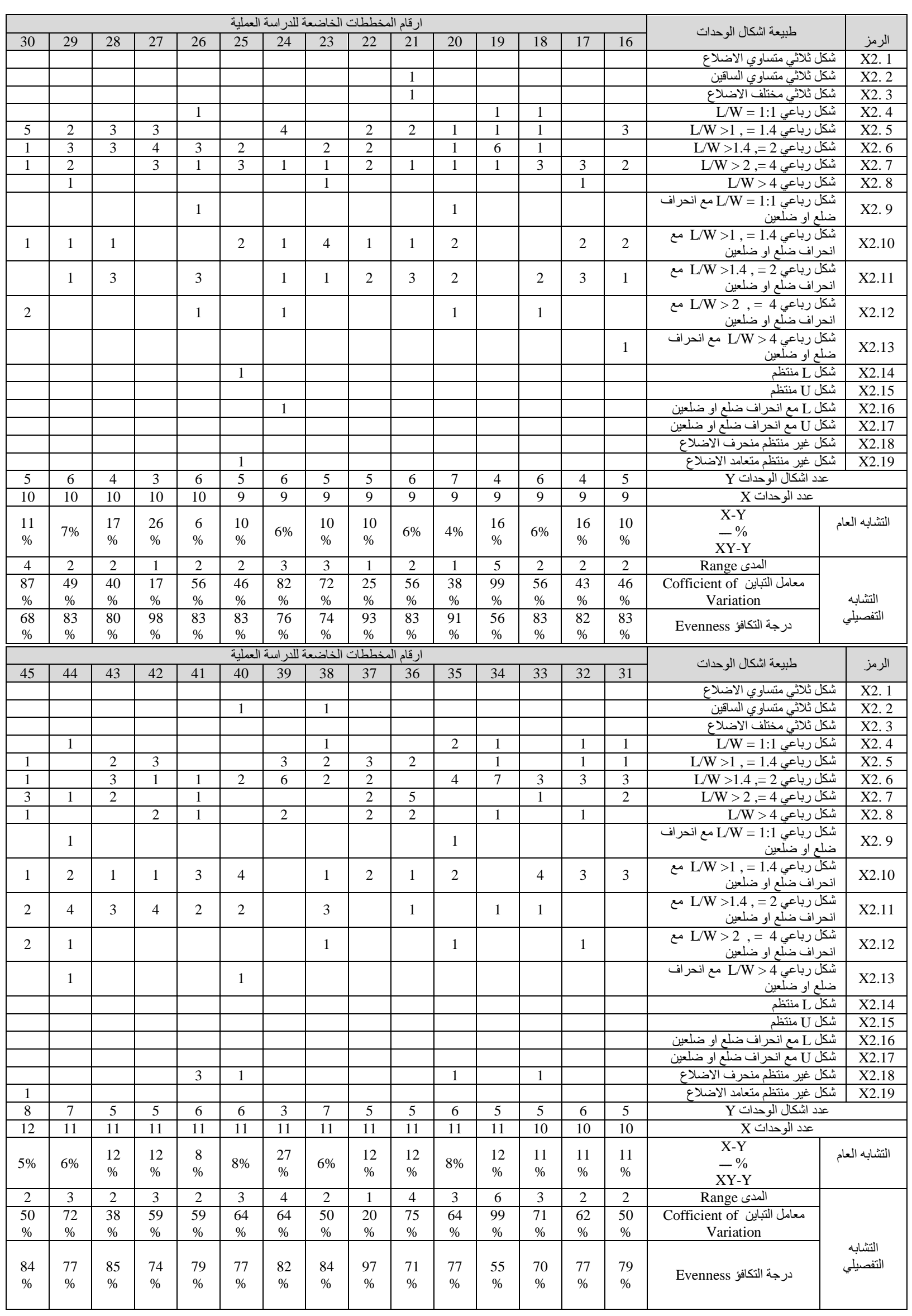


الجميل: خاصية التثابه في مخططات المساكن التقليدية في مدينة الموصل القديمة

\begin{tabular}{|c|c|c|c|c|c|c|c|c|c|c|c|c|c|c|c|c|c|}
\hline \multicolumn{15}{|c|}{ ارقام المخططات الخاضعة للار اسة العملية } & \multirow{2}{*}{\multicolumn{2}{|c|}{ طبيعة اشكال الوحدات }} & \multirow{2}{*}{ 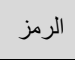 } \\
\hline 60 & 59 & 58 & 57 & 56 & 55 & 54 & 53 & 52 & 51 & 50 & 49 & 48 & 47 & 46 & & & \\
\hline & & & & & & & & & & & & & & & \multicolumn{2}{|c|}{ شكل ثلاثي متساوي الاضلاع } & $\mathrm{X} 2.1$ \\
\hline & & & & & & & & & & & & & 1 & & \multicolumn{2}{|c|}{ شكل ثلاثي متساوي الساقين } & $\mathrm{X} 2.2$ \\
\hline & & & & & & & & & & & & & & 1 & \multicolumn{2}{|c|}{ شكل ثلاثي مختلف الاضلاع } & $\mathrm{X} 2.3$ \\
\hline & & 1 & 1 & 1 & & & & & 1 & & & & 1 & & \multicolumn{2}{|c|}{ شكل رباعي 1:1 = شك } & $\mathrm{X} 2.4$ \\
\hline 2 & 2 & 7 & 2 & 3 & 4 & 4 & 4 & 1 & 3 & 2 & 3 & 1 & 3 & 2 & \multicolumn{2}{|c|}{ L/W >1, = شكل رباعي 1.4} & $\mathrm{X} 2.5$ \\
\hline 2 & 4 & 3 & 5 & 5 & 5 & 1 & 2 & 1 & 4 & 3 & 2 & 3 & & 4 & \multicolumn{2}{|c|}{ شكل رباعي $2=, 4.4$ L/W } & $\mathrm{X} 2.6$ \\
\hline & 1 & 2 & 1 & & & 3 & 1 & 3 & 2 & 4 & 1 & & 1 & & \multicolumn{2}{|c|}{ شكل رباعي $4=2,2 / W>2$} & $\mathrm{X} 2.7$ \\
\hline & & 1 & & & 2 & 2 & 1 & & 1 & & 1 & 2 & & 3 & \multicolumn{2}{|c|}{ شكل رباعي 4 اع } & $\mathrm{X} 2.8$ \\
\hline & 1 & & & 1 & & & & & & & & & & & \multicolumn{2}{|c|}{ 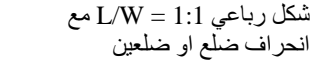 } & $\mathrm{X} 2.9$ \\
\hline 5 & 2 & & 3 & 3 & & 2 & 2 & & & 1 & 2 & 1 & 2 & & \multicolumn{2}{|c|}{ 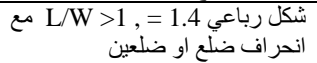 } & $\mathrm{X} 2.10$ \\
\hline 3 & 5 & 1 & 2 & & 2 & 1 & 3 & 5 & & 2 & 1 & 2 & 2 & & \multicolumn{2}{|c|}{ 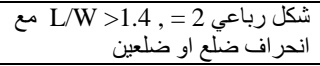 } & $\mathrm{X} 2.11$ \\
\hline & & & & & 1 & & & 2 & & & & 1 & 1 & & \multicolumn{2}{|c|}{ 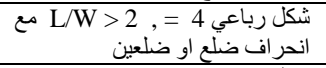 } & $\mathrm{X} 2.12$ \\
\hline & & & & & & 1 & & & & & & & 1 & & \multicolumn{2}{|c|}{ 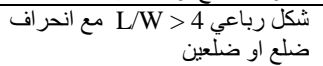 } & $\mathrm{X} 2.13$ \\
\hline & & & & & & & & & 2 & & 3 & 1 & & & \multicolumn{2}{|c|}{ شكل L منتظم } & $\mathrm{X} 2.14$ \\
\hline & & & & & & & & & & & & & & & \multirow{2}{*}{\multicolumn{2}{|c|}{ شكل U U معنظم انتحر ضلع او ضلعين }} & $\mathrm{X} 2.15$ \\
\hline 2 & & & & & & & & 1 & & 1 & & 1 & & 2 & & & $\mathrm{X} 2.16$ \\
\hline & & & & & & & & & & & & & & & \multicolumn{2}{|c|}{ شكل U مع انحر اف ضلع او ضلعين } & $\mathrm{X} 2.17$ \\
\hline 1 & & & & & & & & & & & & & & & \multicolumn{2}{|c|}{ شكل غير منتظم منحرف الاضلاع } & $\mathrm{X} 2.18$ \\
\hline & & & & 1 & & & & & & & & & & & \multicolumn{2}{|c|}{ شكل غير منتظم متعامد الاضلاع } & $\mathrm{X} 2.19$ \\
\hline 6 & 6 & 6 & 6 & 6 & 5 & 7 & 6 & 6 & 6 & 6 & 7 & 8 & 8 & 5 & \multicolumn{3}{|c|}{ عدد اثكال الوحدات Y ع } \\
\hline 15 & 15 & 15 & 14 & 14 & 14 & 14 & 13 & 13 & 13 & 13 & 13 & 12 & 12 & 12 & \\
\hline $\begin{array}{l}11 \\
\%\end{array}$ & $\begin{array}{l}11 \\
\%\end{array}$ & $\begin{array}{l}11 \\
\%\end{array}$ & $\begin{array}{l}10 \\
\%\end{array}$ & $\begin{array}{l}10 \\
\%\end{array}$ & $\begin{array}{l}14 \\
\%\end{array}$ & $8 \%$ & $\begin{array}{l}10 \\
\%\end{array}$ & $\begin{array}{l}10 \\
\%\end{array}$ & $\begin{array}{l}10 \\
\%\end{array}$ & $\begin{array}{l}10 \\
\%\end{array}$ & $7 \%$ & $5 \%$ & $5 \%$ & $\begin{array}{l}13 \\
\%\end{array}$ & \multicolumn{3}{|c|}{ X ع عد الوحدات X } \\
\hline 4 & 4 & 6 & 4 & 4 & 4 & 3 & 3 & 4 & 3 & 3 & 2 & 2 & 2 & 3 & Range المدى & \multirow{3}{*}{\multicolumn{2}{|c|}{ التشابه التفصيلي }} \\
\hline 55 & 66 & 94 & 65 & 70 & 59 & 58 & 54 & 74 & 54 & 54 & 48 & 50 & 50 & 48 & \multirow{2}{*}{$\begin{array}{l}\text { Cofficient معامل التباين } \\
\text { of Variation }\end{array}$} & & \\
\hline$\%$ & $\%$ & $\%$ & $\%$ & $\%$ & $\%$ & $\%$ & $\%$ & $\%$ & $\%$ & $\%$ & $\%$ & $\%$ & $\%$ & $\%$ & & & \\
\hline
\end{tabular}

رابعاً: نتائج التحليل العنقودي Cluster Analysis

\begin{tabular}{|c|c|c|c|c|c|c|}
\hline مستوى التثابه \% & \multicolumn{2}{|c|}{ ارقام المخططات المتثابهة } & \multirow{2}{*}{$\begin{array}{l}\text { مستوى التثشابه } \\
\text { Similarity level } \\
84.81\end{array}$} & \multicolumn{2}{|c|}{ ارقام المخططات المتثابهة } & \multirow{2}{*}{ 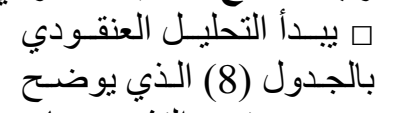 } \\
\hline 72.26 & 25 & 14 & & 10 & 7 & \\
\hline 72.26 & 20 & 2 & 82.46 & 9 & 8 & 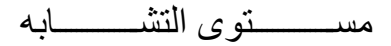 \\
\hline 72.26 & 17 & 8 & 82.46 & 4 & 3 & Similarit \\
\hline 72.26 & 14 & 2 & 80.39 & 29 & 22 & Simmiari \\
\hline 72.26 & 8 & 2 & 78.52 & 43 & 22 & مخططـات \\
\hline 72.26 & 6 & 2 & 78.52 & 33 & 23 & تَنـانه 100\% \\
\hline 72.26 & 2 & 1 & 78.52 & 27 & 7 & \\
\hline 70.91 & 50 & 1 & 78.52 & 5 & 3 & \\
\hline 70.91 & 47 & 38 & 76.8 & 32 & 31 & لـلـ فـــي قــيم \\
\hline 70.91 & 42 & 1 & 76.8 & 28 & 22 & • المخطظطات. \\
\hline 70.91 & 38 & 1 & 76.8 & 24 & 13 & 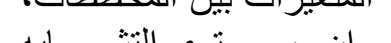 \\
\hline 70.91 & 21 & 1 & 76.8 & 22 & 18 & لـى الستـــــــابه \\
\hline 69.62 & 41 & 1 & 76.8 & 19 & 12 & كلما قل التشابه بين \\
\hline 68.38 & 53 & 1 & 76.8 & 12 & 7 & I. \\
\hline 68.38 & 51 & 49 & 76.8 & 11 & 8 & قعل \\
\hline 68.38 & 48 & 1 & 75.19 & 31 & 23 & جدول \\
\hline 67.18 & 44 & 1 & 75.19 & 18 & 15 & d \\
\hline 67.18 & 39 & 1 & 75.19 & 15 & 7 & \\
\hline 66.03 & 54 & 1 & 73.69 & 40 & 23 & طـات هـو بـين \\
\hline 66.03 & 49 & 1 & 73.69 & 37 & 7 & المخططين (7 و 10) ققيـة \\
\hline 64.92 & 59 & 56 & 73.69 & 34 & 7 & 0 \\
\hline 64.92 & 45 & 1 & 73.69 & 30 & 13 & 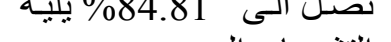 \\
\hline 62.79 & 46 & 1 & 73.69 & 26 & 7 & التشــــابه الموجــــود بــين \\
\hline 60.78 & 36 & 1 & 73.69 & 23 & 7 & $\ddot{a} \quad 0$ o) \\
\hline 60.78 & 56 & 1 & 73.69 & 16 & 13 & (1) \\
\hline 60.78 & 52 & 1 & 73.69 & 13 & 6 & صـــل الـــى $82.46 \%$ \\
\hline 59.81 & 55 & 1 & 73.69 & 7 & 2 & هك ذـا بالنســـــة لـــــاقـ \\
\hline 57.03 & 60 & 1 & 73.69 & 3 & 1 & \\
\hline 57.03 & 58 & 1 & 72.26 & 57 & 56 & المحطط \\
\hline & & & 72.26 & 35 & 2 & 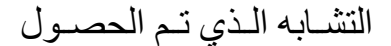 \\
\hline
\end{tabular}

عليه موضح بيانياً في المخطط الثجري Tree Diagram المبين في الثكل (5) اذ يمثل المحور السيني المخططسات 
التقليدية اما المحور الصادي فيمثل مستوى التشابه ويلاحظ ان نقطة الاصل في هذا المحور تمثل اعلى تثـابه مكن وهو $.100 \%$

الجدول (8): نتائج التحليل العنقودي للمخططات التقليدية

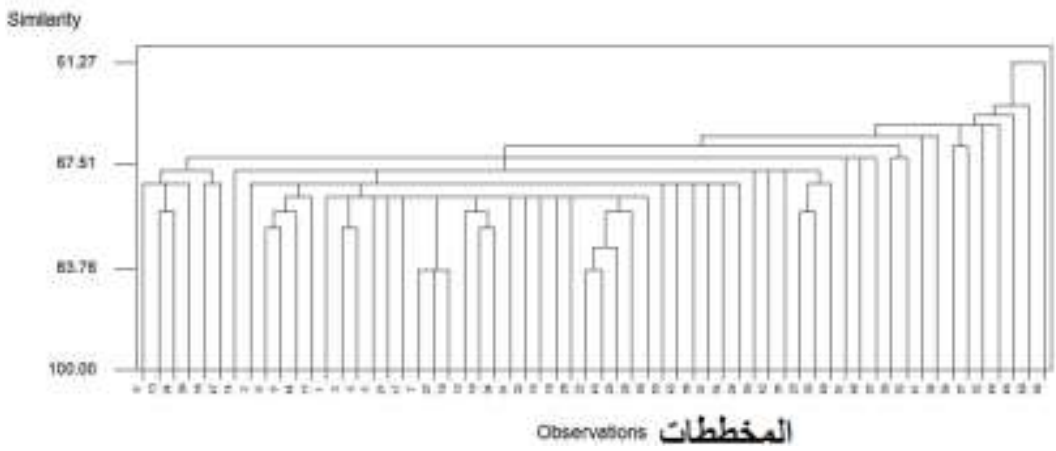

الثكل (5): المخطط الثجري للتحليل العنقودي للمخططات التقليدية

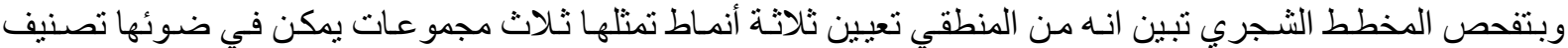

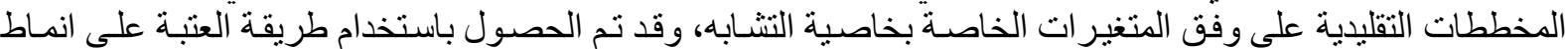
التشابه التي تتمثل بالمجمو عات الآلتية التية:

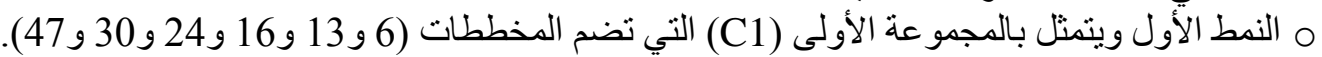

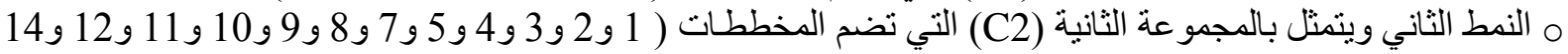

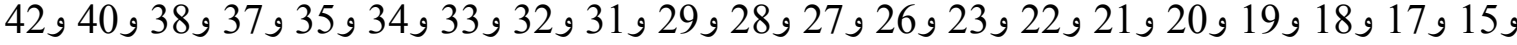

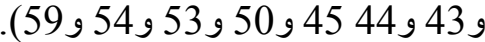
م النمط الثنالث ويتمثل بالمجمو عـة الثالثة (C3) التي تضم المخططـات (25 و36 و39 و و 41 و و46 و48 و49 و 51 و52 و55 و56 و5756 و58,

7. الإستنتاجات والتوصيات:

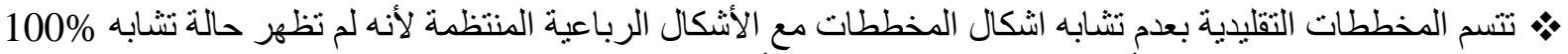
في اشكال المخططات مـع الأشكال الرباعية المنتظمـة، وأن نسبة التشـابه بين

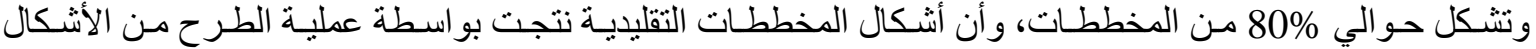

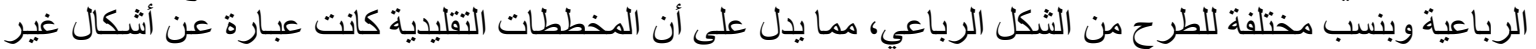

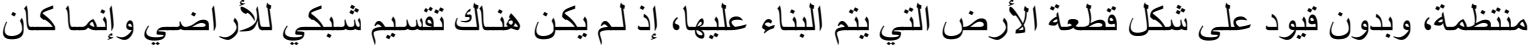

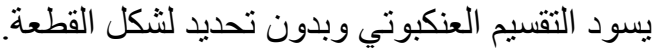

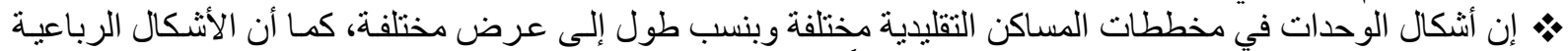

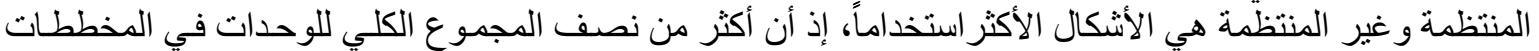

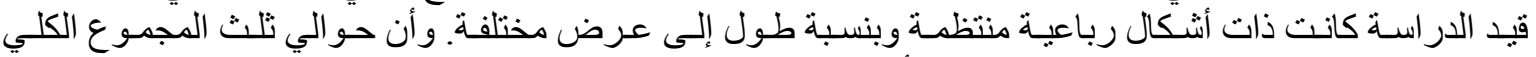

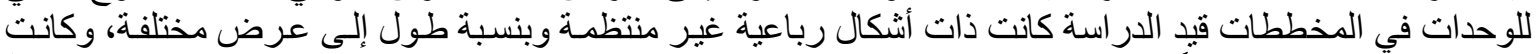

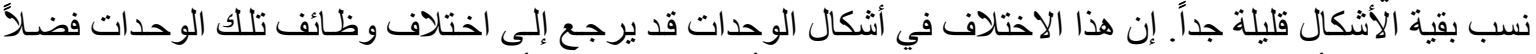

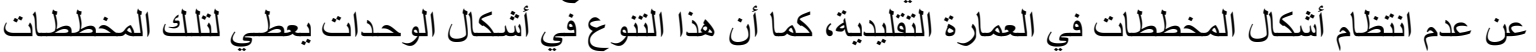

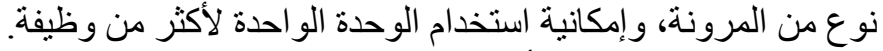

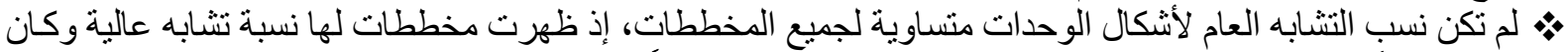

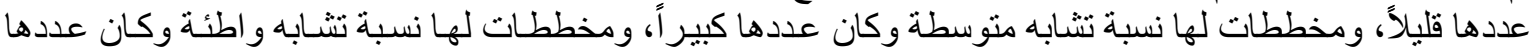

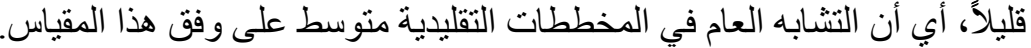

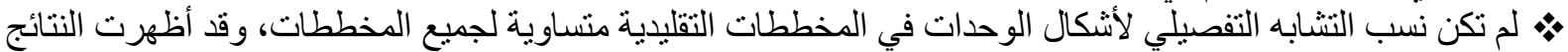

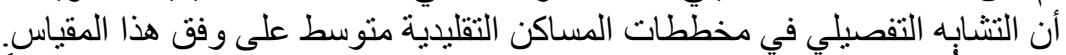

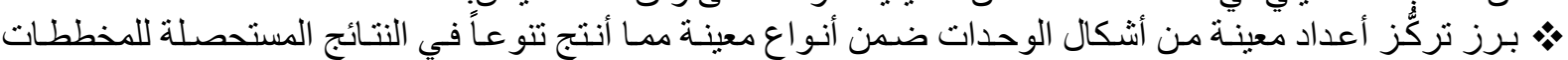

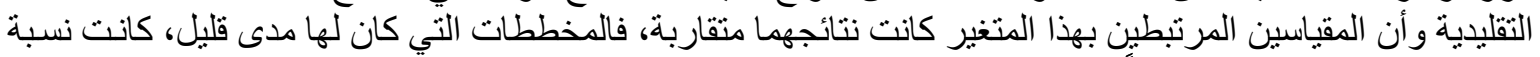




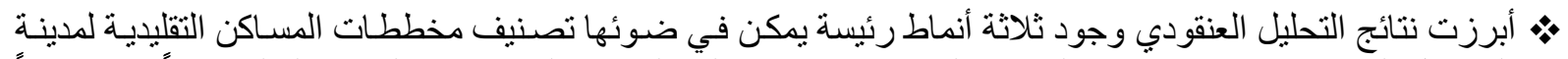

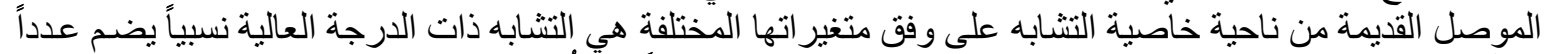

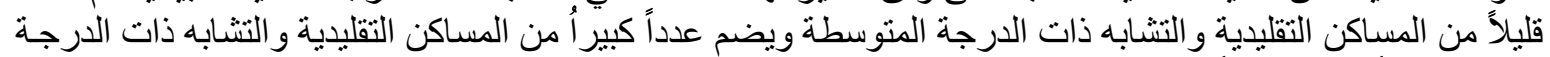

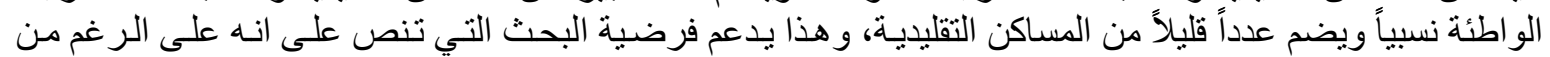

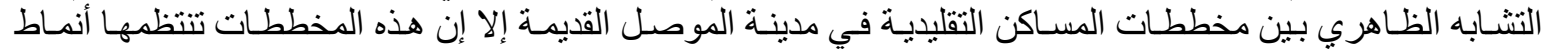

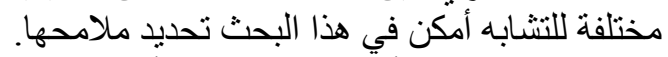

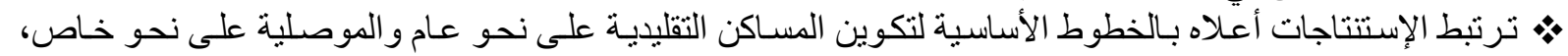

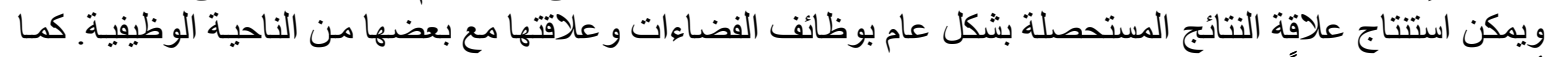

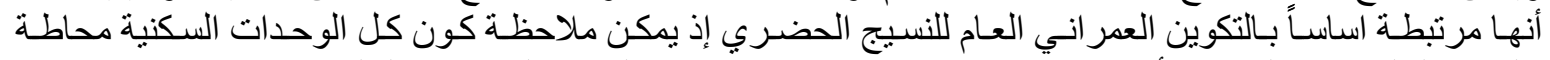

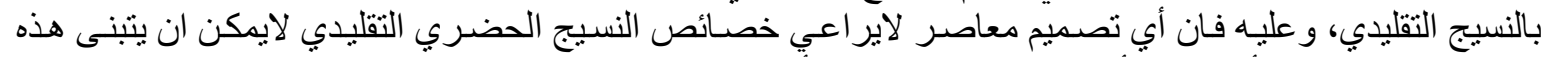

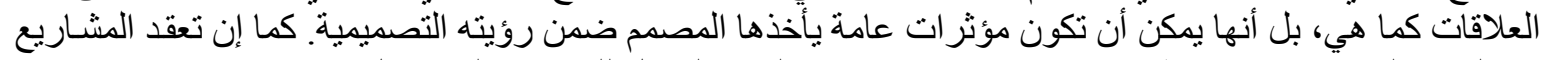

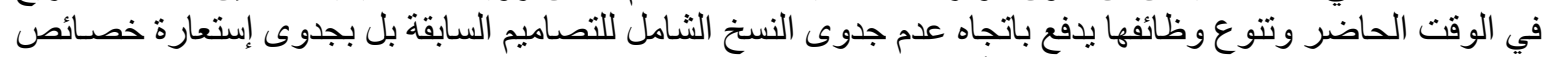
معينة منها وتثكيلها وجمعها مع خصائص أخرى ضمن ظروف وناه ومنطلبات المشروع التصميمي الجديد.

المصادر:

1. البيروتي، د.فائز عبد الحميد، "التطور المعماري للبيت في بغداد"، أطروحة دكتوراه غير منشورة، قسم الهندسة

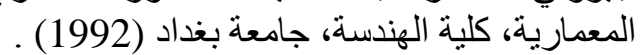

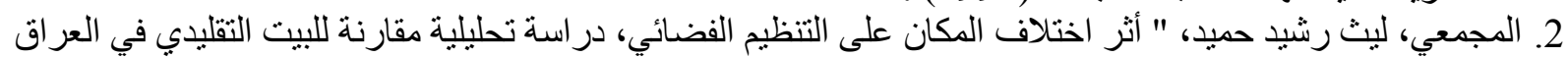

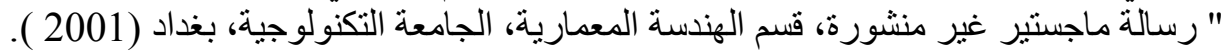

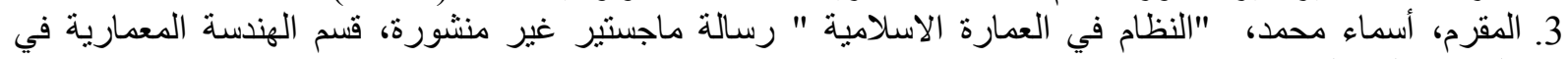

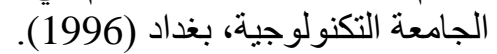

4. المقرم، أسماء محمد، "خصائص عمارة القصار القصور الاسلامية"، مجلة الكوفة، مركز دراسات الكوفة، وقائع مؤتمر الفكر المعماري الإسلامي، (آيار 2001).

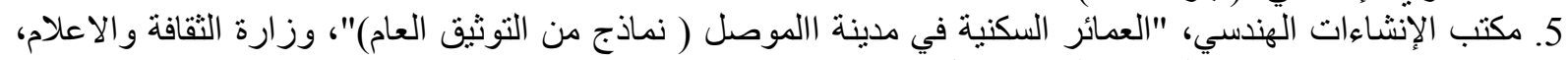

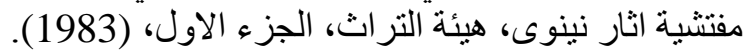

6. يوسف، شريف، "تاريخ فن العمارة العراقية في مختلف العاولف العصور"، دار الرشيد للنشر، منشورات وزارة الثقافة و الاعلام، العراق، (1982).

7. Al-Nijaidi, H., "Flexibility in the Design of Building", PhD Thesis, Oxford Polytechnic, (1985).

8. Gero, J. S., "Shape pattern recognition using a computable shape pattern representation", Artificial Intelligence in Design '98, Kluwer, Dordrecht, (1998).

9. Herdeg, Clause, "Past , Present and Future : Alternative Methods of Analysis" in Theories and Principles of Design in the Architecture of Islamic Societies, A Symposium held by the Aga Khan, (1988).

10. March L. \& Steadman P., "Architectural Morphology: An Introduction to the Geometry of Building Plans”, Pion, London, (1983).

$$
\text { تم اجراء البحث في كلية الهنثسة = جامعة الموصن }
$$




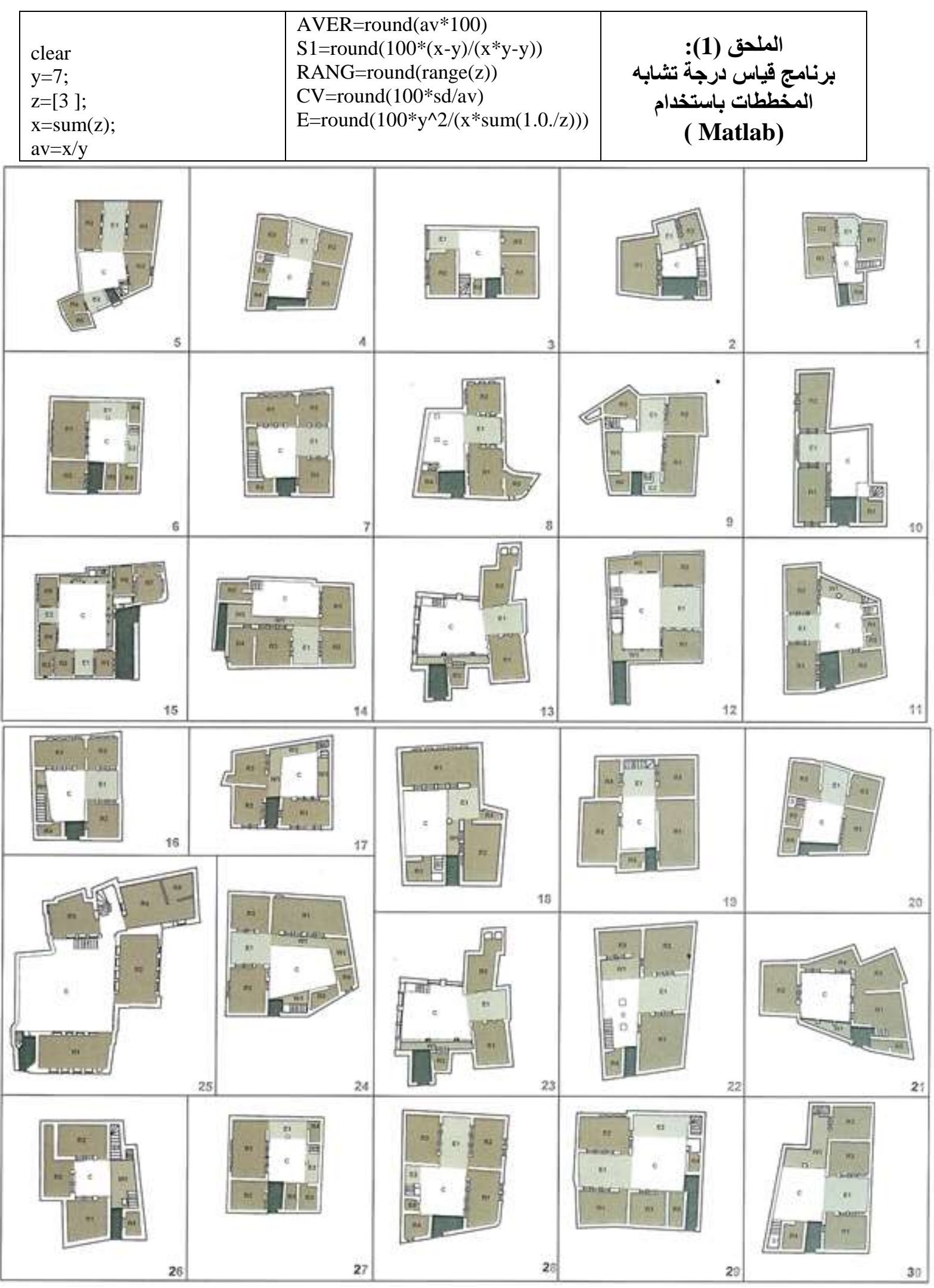


الجميل: خاصية التثابه في مخططات المساكن التقليدية في مدينة الموصل القديمة

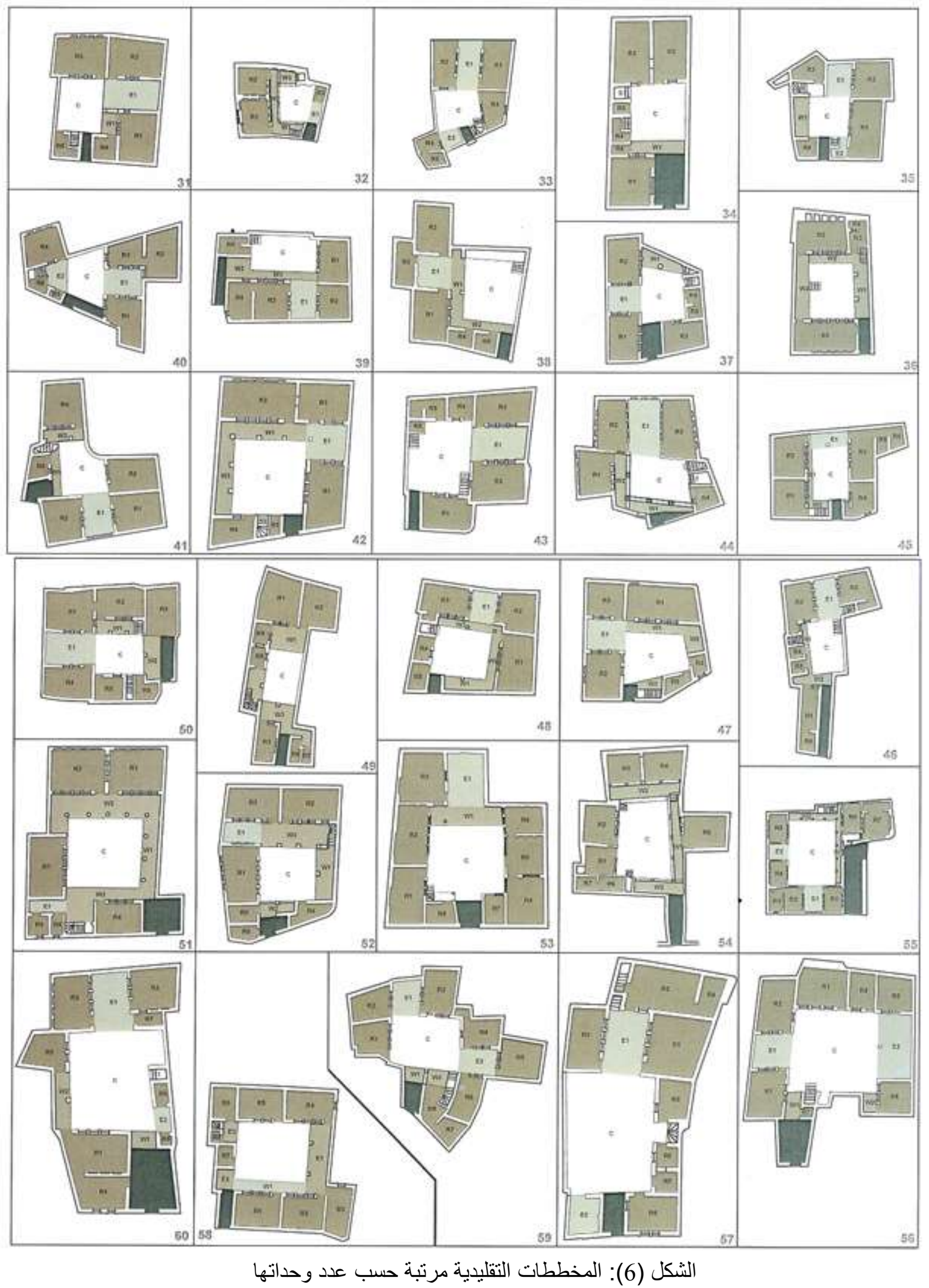

